XII. The Myology of the Upper and Lower Extremities of Orycteropus Capensis. By John Charles Gation, Esq., M.A., Exeter College, Oxford.

(Plates XLV.\& XLVI.)

Read June 4th, 1868.

A REMARKABLY fine adult male specimen of Orycteropus Capensis" (the "Aardvark" of Dutch colonists) having been presented to the University Museum, Oxford, by W. A. Sandford, Esq., F.G.S., of Nynehead Court, Somerset, I have been enabled, by the kind permission of Prof. Rolleston, F.R.S., to examine the muscular system of this animal.

The rarity of the beast, the great size of the specimen, and the fair condition, in most respects, of its muscles, and, finally, the hope of being able to throw even yet some light here and there upon its anatomy, since they were the reasons which encouraged me in the undertaking, are the excuses which I offer to this Society for bringing forward the results of what may appear to some a work of supererogation, seeing that a paper on the myology of the Orycteropus, by Prof. Humphry, of Cambridge, was published but lately in the journal which he conducts as joint editor ${ }^{2}$.

Cuvier has the priority of Prof. Humphry in investigation of the myology of Orycteropus; but no complete record of his observations, if ever written, appears to be extant. He has, however, left nine figures, which are comprised in three plates, illustrating the anatomy of this animal, as a testimony of his labours ${ }^{3}$.

The specimen which I am about to describe weighed 95 lbs. The viscera and external genitals had been removed; and it had been conveyed to England in spirit.

The principal measurements were as follows :- From tip of snout to extremity of tail, $68 \frac{1}{2}$ inches; from tip of tail to lower border of pubic symphysis, 25 inches (the neighbourhood of the anus had been so involved in the incisions which had been made for the removal of the genitals, that $I$ had no better fixed point from which to take a measurement); from labial commissure to anterior angle of eyelids, $3 \frac{7}{8}$ inches; from

1 For figures of the animal, see :-Rapp's 'Anatomische Untersuchungen über die Edentaten,' Tübingen, 1852, Taf. i.; Daniell's 'Sketches representing the native Tribes, Animals, and Scenery of Southern Africa,' London, 1820, plate ii. (the drawings, though somewhat rude, are no doubt very trustworthy, since they were taken in the country itself); Cuvier's 'Règne Animal' (Mammifères), pl. 73 (the figure here given was taken from a stuffed specimen) ; ' English Cyelopædia,' (Nat. Hist.) vol. i. fig. 1, art. AARD-VARK.

There is a description of this animal at p. 342, vol. i. of Burchell's 'Travels in the Interior of Southern Africa' (2 vols. Lond. 1822). The vignette at the head of chap. 18, p. 446 of the same volume, represents ant-hills, one of which has been broken into at the side by the Aard-vark. The Hottentot name for this animal (op. cit. vol. ii. p. 424) is Taklsarú.

2 Journ. of Anat. and Phys. (2nd ser.) vol. i. p. 290. Cambridge, 1868.

${ }^{3}$ Cuvier, Laarillard et Mercier, ‘Anatomie Comparée, recueil de planches' (fol.), pls. 254-256. Paris, 1855. VOL. XXVI. 
posterior angle of eyelid to anterior border of concha of ear, 4 inches; from anterior border of concha to tip of ear, 7 inches; from posterior border of calcaneum to tip of nail of middle toe (plantar surface), $10 \frac{1}{2}$ inches ; from anterior border of radius, or posterior border of wrist, to extremity of longest digit (dorsal measurement), $7 \frac{3}{4}$ inches.

The "manus" in this animal has only four digits, the pollex being rudimentary. The homologue of the "middle" digit is the longest, the index being shorter, but of very nearly equal length. This character serves to distinguish O. Capensis from the only other species, EE. Athiopicus". The homologue of the "fourth" finger comes next in size, the little finger being by far the shortest.

The "pes" has a large oval callosity in the centre of the sole. The heel is extremely well marked, and is, moreover, covered on its plantar aspect with a callous pad. This character, taken together with the plantar callosity, indicates obviously a plantigrade mode of progression. Such a conclusion is supported by Daniell's figures, to which reference has already been made ${ }^{2}$.

Five digits are present, of which the middle is the longest, the second being shorter, but very nearly of the same length. The hallux comes next in size; the root of its nail is in a line with the tip of the little toe.

UPPER EXTREMITY.-Though the arm is more easily abducted from the side than is the fore limb in the Armadillo described by me, the extension of the forearm from the upper arm is, nevertheless, much limited, chiefly in consequence of the attachment of the strong platysma along the outer aspect of the former.

I must here crave indulgence for a looseness and seeming uncertainty in my descriptions of certain muscles, seeing that $I$ had no skeleton at hand while dissecting (a guide of which those alone know the value who have ever dissected much)-my sole osteological aid being derived from the plate of the skeleton of the Orycteropus contained in Cuvier's 'Ossemens Fossiles,' which I had always at my side when at work, and from a single short visit to the actual skeleton of this animal at the Museum of the Royal College of Surgeons. The more precise descriptions are founded upon more certain observations, and are, therefore, I hope, the more worthy of trust.

Musculus sternalis brutorum (or superficial layer of panniculus carnosus).-This is exceedingly well developed in the Orycteropus, and extends from the labial commissure to the lower extremity of the thorax. In the region of the head and neck its fibres are delicate and pale; but when the chest is reached, they become coarse and darker in colour, the bulk of the muscle being at the same time increased.

At the commissure of the lips the fibres of the muscle appear to diverge, forming or sending contributions to a kind of orbicularis oris. Thence they pass, uniform in breadth, along the buccal interspace between the upper and lower jaws; but on reaching the

1 Rapp, op. cit. p. 13. Mr. Andrew Murray, however, in a "Synonymic List of Species of Mammals and their Localities," appended (p. 341) to his 'Geographical Distribution of Mammals' (Lond. 1866), mentions three species of Orycteropus, namely:-O. Ethiopicus, Sund., S. Nubia, near the White Nile; O. Capensis, Geoffr., Caffraria, S. W. Africa ; O. Senegalensis, Less., Senegal.

2 In pl. 53 of 'Shaw's Zoology' (Mammalia), vol. i. part i. (Lond. 1800), the Orycteropus is plainly represented as plantigrade. 
cervical region, immediately after passing beyond the inferior extremity of the vertical ramus of the mandible, they spread out, and soon give off from the outer side a branch of fibres, which curve gradually outwards and downwards, and, passing over the deeper layer of the panniculus carnosus, are lost in the dense fibro-adipose subcutaneous tissue of the neck.

Immediately underneath the muscle, during the whole extent of its passage along the neck, lies the enormously developed submaxillary gland, the strong fibrous capsule of the latter only intervening.

On reaching the anterior border of the chest, the muscle narrows in breadth, but increases in thickness, and, passing over the insertion of the sterno-mastoid and manubrial portion of the pectoralis major, is inserted into the middle line of the sternum, from immediately below the insertion of the former muscle to about the beginning of the posterior or inferior third of the bone, its fibres meeting those of its fellow in the middle line, but not decussating with them.

A few fibres seem to be prolonged into the fascia covering the abdomen; and a few others are given off from the outer edge of the muscle, on a level with its lowest point of insertion, to be lost over the ascending fibres of the dermo-humérien.

Since this muscle coexists with an upward extension of the rectus abdominis, and with a downward prolongation of the sterno-mastoid, the only alternative left is to regard it, with Halbertsma, as a muscle sui generis, or to agree with Professor Turner ${ }^{1}$ in considering it a differentiated portion of the panniculus carnosus-a conclusion in which I am inclined to concur.

Prof. Humphry, though he has given a full description and a good representation (loc. cit. pl. 13) of the panniculus carnosus ${ }^{2}$, has not considered the factor just described in the light of its bearings upon the question of the nature and affinities of the musculus sternalis.

Cuvier, in his plates of the Orycteropus ${ }^{3}$, gives a good representation of this muscle, under the name of "thoraco-facien." It is figured on the inner of two divisions of the platysma, the outer of which passes over to the external aspect of the arm and forearm, and is termed by him "dermo-humérien."

Platysma myoides.-This element of the panniculus carnosus is very well developed, and consists of a strong and somewhat coarse muscle, which arises from the whole extent of the inferior edge of the jugal arch and, seemingly, in part from the body of the malar bone, passes downwards and outwards over the shoulder, and along the outer aspect of the arm, to be inserted, along the radial edge of the forearm, in the fascia which clothes its external aspect. At the middle of its course it is crossed by a band of muscular fibres, which curve outwards and downwards from the outer edge of the musculus sternalis to be finally lost in the subcutaneous tissue of the neck.

1 "On the Musculus Sternalis," Journ. of Anat. \& Phys., Cambridge, 1857, 1st ser. vol. i. p. 246. To the animals cited by Prof. Turner in support of his views, at p. 253 in the above paper, I am able to add from my own obserrations Hystrix (cristata?). The muscle in question is well represented by Cuvier, under the name of "thoracofacien," in his figures of this animal, op. cit. pl. 228.

2 Loc. cit. p. 292.

${ }^{3}$ Op. cit. pl. 254. fig. 1, pl. 255. 
A little further on, this muscle appears to enter into a more or less intimate connexion with the under surface of the musculus sternalis, before this latter broadens out in the cervical region.

This muscle is well represented by Cuvier ${ }^{1}$, under the name of dermo-humérien.

Rhomboidei.-These are scarcely to be differentiated except by a slight difference in the arrangement of their muscular fibres, the $r$. minor being coarser in texture than its fellow. The $r$. minor takes origin from the occipital crest, and from the side of the nuchal ligament, along its whole length, and is inserted into the superior angle of the scapula, and into a very small adjoining portion of the base of the bone,

This muscle is represented by Cuvier" under the name of "rhomboide du cou."

The $r$. major arises fleshy from the spine of the "vertebra prominens" (1st dorsal), and from those of the three succeeding vertebra, also from an aponeurosis covering the deeper dorsal muscles, and covered in turn by the trapezins. It is inserted along the whole of the posterior costa of the scapula.

Levator anguli scapule. - This muscle consists of two portions, the smaller of which is a slip of uniform breadth arising from the transverse process of the atlas, beneath the origin of the acromio-basilar, but fused with it. It was inserted into the posterior part of the fascia covering the supraspinatus. The bulk of the muscle seemed to take origin from the transverse processes of the cervical vertebræ, from the second to the fifth inclusive, and was inserted into the upper angle of the base of the scapula, fusing with the superior portion of the inserted part of the serratus magnus, as described by Prof. ; Humphry ${ }^{3}$.

The first-mentioned factor of this muscle may answer, I think, to the occipito-scapular, which I have described as having so enormous a development in Dasypus sexcinctus.

Serratus magnus. - Had no peculiarities worthy of note, excepting that, besides taking origin from the first eight ribs, it seemed also to arise from the transverse processes of the two lowest cervical vertebre, assuming thus the appearance of a downward continuation of the levator anguli scapula. It is inserted into the inner aspect of the scapula, close to the basal margin.

Acromio-basilar.-This muscle, termed by Prof. Humphry "cervico-humeral," arose from the transverse process of the atlas, and was inserted into the " metacromial process" (Parker) of the scapula. During nearly the whole of its course it ran in close relation to the free edge of the cervical portion (Cuvier) of the trapezius, and, just before insertion, was nearly fused with it.

Cuvier gives a very good representation of this muscles, under the designation of "acromio-" or "omo-trachélien." It may be worth noting that in this author's figure of the Armadillo the symbol of a factor ("portion cervicale") of the trapezius is attached to the homologue of this muscle.

The acromio-basilar may, after all, be regarảed, as Meckel long ago suggested ${ }^{7}$, as but a differentiated portion of the trapezius.

Trapezius.-This muscle appeared to take origin, as far as I could ascertain without

Op. cit. pl. 254. fig. 1, and pl. 255.

+ Ibid. p. 298.

z 'Syst. der vergleich. Anat.' Halle, 1828, dritt. Theil, p. 481.
3 Loc. cit. p. 299.

6 Ibid. pl. 259. fig. 2. 
the assistance of a skeleton at hand, from the lumbar aponeurosis, from the spines of the first nine dorsal vertebræ, and from the nuchal ligament, being covered at the highest, point of origin, as Prof. Humphry remarks', by the retractor auris. Its anterior half is inserted fleshy into the upper edge of the anterior half of the scapular spine, being almost continued here into the scapular division of the deltoid, and having a small layer of fibres detached from its inferior surface to be inserted into the fascia covering the supraspinatus muscle.

The rest of the trapezius radiates towards an irregularly oval aponeurosis, which is inserted into the broadened-out tubercle or facet developed midway upon the spine of the scapula.

The most anterior inserted portion of the muscle is in intimate relation with the terminal part of the acromio-basilar.

The trapezius has no clavicular insertion whatever.

Omo-hyoid.-This muscle, as was the case in Dasypus, is absent. Prof. Humphry makes no remark concerning either its presence or absence; nor is it figured by Cuvier.

Euvier does not mention this muscle when describing the hyoidean myology in Dasypus. He says, however, that in the Sloths it is entirely absent (" manque toutà-fait" ${ }^{2}$ )

It is remarked in Cuvier's 'Leçons' 3 that the omo-hyoids are wanting in the Sloths. They are described in the Anteater; but no mention is made of either their presence or absence in the Armadillo. Prof. Owen, in his description of the muscles of the tongue of the Great Anteater, makes no mention of this muscles. I conclude, therefore, that it is absent in this animal.

The levator clavicula, which was present in the Armadillo, is absent in Orycteropus.

Sterno-mastoid.-The bulk of this muscle had its ordinary origin from the mastoid process of the temporal bone, and was inserted along the upper edge of the manubrium sterni. On its middle third rested the principal lobe of the submaxillary gland.

Another and smaller section of the muscle took origin, or was inserted, along the whole of the middle line of the manubrium, meeting with its fellow of the opposite sidean arrangement similar to that in the Armadillo. It then ran along the outer edge of the first-described section of the muscle, fusing with it, but on reaching the upper part of the neck was separated from it by the jugular vein, which passed between. At the root of the ear it terminated, serving as a kind of depressor auris-an arrangement very clearly represented by Cuvier in one of his plates ${ }^{5}$.

The cleido-mastoid, which rises beneath the above, from the mastoid process, runs along on its outer side for the greater part of its course, but, finally diverging, is inserted into the sternal half of the clavicle.

Subclavius.-This is a very well developed muscle, taking origin from the manubrium of the sternum, and from the junction of the first rib with this bone-in part, too, by

${ }^{2}$ Loe. cit. p. 298.

2 Anat. Comp. vol. viii. p. 563.

3 2nd edit. Paris, 1835, tome iv. $1^{\mathrm{e}}$ partie, p. 490.

4 "On the Anatomy of the Great Anteater," Trans. Zool. Soc. July 1854.

5 Op. cit. pl. 255. 
means of a slight, but distinct, downward prolongation of some of its fibres, from the terminal aponeurosis of the rectus abdominis, which finds insertion at the first rib.

It then passes, rolled upon itself, under the clavicle, to be inserted aponeurotically along the upper border of the acromial half of this bone, into a kind of sesamoid ${ }^{1}$ situated just below the acromio-clavicular joint, and which is imbedded in the fibres of origin of the deltoid, along the acromion itself, and into the fascia covering the supraspinatus muscle; while a thin stratum, derived from the lower portion of the muscle, finds insertion by aponeurosis along the inner edge of the strong coraco-acromial ligament.

This mode of insertion of the subclavius bears great resemblance to that of its homologue in the species of Dasypus already described by me.

The muscle, at its insertion, is fairly represented by Cuvier in one of his plates ${ }^{2}$.

Prof. Rolleston considers that the ventral portion of the muscle, through the intermediation of fascia covering the external surface of the acromion, can act, as in the Guineapig, upon the acromial portion of the deltoid.

With regard to the significance of the origin of part of the subclavius from the terminal tendon of the rectus abdominis, and its bearings upon the possible homology of the former muscle with the levator humeri of Birds, both detail and generalization will be found in a forthcoming paper by Dr. Rolleston "on the Homologies of certain Muscles connected with the Shoulder-joint"

I could not determine with certainty, in the specimens of Dasypus sexcinctus which I examined, whether the lowest fibres of origin of the subclavius were in any wise continuous with the terminal fibres of the rectus abdominis, which muscle had a fleshy (instead of an aponeurotic) insertion at the first rib, at the very foot of the origin of the subclavius ${ }^{4}$.

Obliquus externus.-Though not strictly a muscle of the upper limb, it may not be out of place to remark here that it extends very high over the chest, its aponeurosis here covering the rectus abdominis almost up to the termination of this latter. Its highest fibres of origin arise from the upper edge of the first rib, between the origin of the $s u b$ -

\footnotetext{
I I had overlooked the presence of this ossicle; but it was pointed out to me by Prof. Rolleston, who, wishing to ascertain, for the support or the establishment of an important anatomical point, the termination of the subelavius in the specimen which I was dissecting, subjected this muscle to a more rigid scruting than I had previonsly done. The ossicle was present on both sides. Prof. Humphry has made no mention of its existence; nor is it figured or described by Cuvier in his 'Ossemens Fossiles.' Rapp, in the osteological portion of his monograph, makes no reference to such a bone; nor is there one present, on either side, in the skeleton of O'ycteropus at the Royal College of Surgeons.

Mr. Parker, moreover, in his monograph on the 'Structure and Development of the Shoulder-girdle and Sternum in the Vertebrata,' published this year by the Ray Society, neither mentions tho presence of this ossicle in the Orycteropus, nor does he represent it in his figures of the shoulder-girdle of this animal (Pl. xxiii. figs. 17 and 18), though the specimen from which these were taken is deseribed as "old."

The ossicle, if not a " sesamoid," may represent the "mesoscapular segment" described by Mr. Parker at p. 195 of the above-quoted monograph.

2 Op. cit. pl. 256 . fig. 5.

${ }^{3}$ Trans. Linn. Soc. vol. xxvi. 1868.

${ }^{4}$ Meckel (Vergleich. Anat. loc. cit. p. 453) mentions that, in the Armadillo (Tati), the rectus alclominis reaches, "ohne Unterbrechung," to the first rib.
} 
clavius (with a few fibres of which muscle it seems to communicate) and the insertion of the scalenus.

Prof. Rolleston has pointed out to me a similar high origin of this muscle in the Crocodile.

Meckel mentions a high origin of the external oblique from the first rib, as existing in the Hedgehog and Raccoon ${ }^{1}$.

In Dasypus sexcinctus this muscle does not appear to arise from a point higher than the third rib, immediately posterior to the cartilage, and in advance of the insertion of the scalenus. In one of Cuvier's plates, however, this external oblique is figured as though taking origin from the first rib, immediately below the lowest fibres of origin of the subclavius ${ }^{2}$.

Deltoid.-This muscle, as in Dasypus, consists of three distinct portions, more or less triangular in shape, which are fairly, but not extensively, developed in proportion to the rest of the muscles of the shoulder. They are as follow:-

a. Clavicular.-A flat, triangular, or fan-shaped slip, arising from the scapular half of the clavicle, from its inferior or anterior edge, its innermost fibres of origin being at the point of attachment of the outermost fibres of insertion of the cleido-mastoid. It then passes downwards, along the anterior aspect of the arm, covering at their insertion the factor of the deltoid next to be described, and the pectoralis major muscle, and becomes tendinous at the level of the lowest point of insertion of the latter. Its tendon, with the exception of a slight aponeurotic communication with the somewhat flattened and attenuated inferior portion of the tendon of the great pectoral, passes straight on, to join and become fused with that of the biceps, and, eventually, to share its insertion.

B. Acromial.-An almost entirely fleshy slip, having half the length of the firstdescribed factor of the deltoid. It arises from the whole inferior edge of the acromial portion of the scapula-namely, the part included between the strong downward-looking "metacromial process" and the free extremity of the acromion. It is inserted into the strongly developed "deltoid ridge" of the humerus, immediately external or posterior to the upper half of the terminal portion of the manubrial factor of the pectoralis major.

$\gamma$. Scapular.-This arises, in part, from the flat oval facet developed upon the spine of the scapula at about the middle of its course, in part from a tendon which takes origin from the anterior half of the scapular spine, and which is also shared by the anterior fibres of insertion of the trapezius. Thence it passes obliquely downwards and forwards, and, on reaching the posterior edge of the "acromial" division of the deltoid, runs into a somewhat broad and thinly llattened tendon, which lies behind the internal face of the above division, and, fusing with it, shares its insertion.

Cuvier most distinctly figures this muscle as made up of three factors, and, moreover, gives the name "deltoïde à l'avant-bras" to that factor which I have termed "clavicular" ${ }^{3}$; but Prof. Humphry ${ }^{4}$ notices only two divisions in the specimen which he has described.

Supraspinatus.-Arises from the supraspinous fossa of the scapula, and has a very broad

I Vergieich. Anat. loc. cit. p. 454.

3 Op. cit. pl. 254. fig. 2.
$=$ Op. cit. pl. 260.

4 Loc. cit. p. 299. 
insertion, partly fleshy, partly tendinous, into the whole of the upper part of the outer tuberosity of the humerus.

Infraspinatus.-A large muscle, having the usual origin in the fossa from which it derives its name. It is inserted into the external tuberosity of the humerus by a broad strong tendon, which, just before its termination, passes over a facet, somewhat reniform in outline, situated on the outer aspect of the tuberosity, a bursa being interposed.

Teres minor.-A short, triangular muscle, arising from the outer edge of the anterior third of the axillary costa of the scapula, and overlapping the anterior half of the origin of the "long" head of the triceps. It passes forwards to be inserted fleshy into the humerus, immediately below the facet mentioned in connexion with the preceding muscle. From the middle of the inferior edge of the muscle passes a strong tendon to the "metacromial process" of the scapula.

Subscapularis.-This muscle takes its usual origin from the inner surface of the scapula, and is inserted by a strong tendon into the inner tuberosity of the humerus.

Teres major. - A somewhat narrow muscle of nearly uniform width, arising from the lower third of the inner edge of the axillary border of the scapula, and being completely fused at origin with the inferior edge of the subscapularis, and with that posterior element of the triceps with which the latissimus dorsi is conjoined, before this latter detaches from itself the dorso-épitrochlien. It passes forwards, being applied closely to the tendon of the latissimus dorsi, to be inserted tendinously into the bicipital groove, a little below the inner tuberosity of the humerus, its tendon lying above that of the lastmentioned muscle, but being slightly overlapped by it on its lower edge.

Rapp describes in the Tamandua a fusion of the tendon of the teres major with the latissimus dorsi, before it terminates at the humerus ${ }^{1}$.

Latissimus dorsi.-This muscle appeared to take origin from strong aponeurotic fascia attached to the lower half of the dorsal portion of the vertebral column covered by the trapezius, also from the lumbar fascia, from which the above muscle also takes origin, and is covered, moreover, by the ascending portion of the dermo-humérien, which is closely adherent to it.

Some fibres arise from the tenth, eleventh, and twelfth ribs, interdigitating with the origins of the obliquus externus. This costal origin does not appear to have existed in Prof. Humphry's specimen.

The muscle then passes upwards to be inserted into the inner edge of the bicipital groove of the humerus, fusing first with the lower border of the teres major, and detaching, just before it becomes tendinous, a large muscular contingent (the dorso-épitrochlien) to the elbow, which unites, before insertion, with the posterior part of the scapular division of the triceps. This dorso-épitrochlien is, moreover, joined by fibres which take origin from the inferior angle of the scapula. These will be more fully noticed in the description of the triceps. The dorso-épitrochlien is most apparent, from the outer aspect of the arm, as belonging to the latissimus dorsi; for, on viewing it from the inner side, it appears more like to an element of the triceps, with the above muscle closely applied to its inner face.

$$
{ }^{1} \text { Op. cit. p. } 47 \text {. }
$$


Both the latissimus dorsi and the teres major are so intimately connected in Myrmecophaga jubata, that Pouchet, in his monograph upon this species of Anteater ${ }^{1}$, thinks it necessary to describe them together. With regard to the terminal portions of these muscles, he says, "Les deux tendons se confondent en partie. Toutefois ce dernier [the latissimus dorsi] s'insère plus haut que le précédent sur le bord de la gouttière bicipitale."

Pectoralis major.-A muscle of large extent. Arises from the manubrium of the sternum and from the rest of the bone, in the middle line, and, besides communicating on its outer side with the latissimus dorsi, is continued into the abdomen, according to Prof. Humphry ${ }^{2}$, and Cuvier's plates ${ }^{3}$, to fuse with the external oblique. The wide and somewhat irregular gap in the abdominal walls of the specimen which I examined, caused by the long median incision, did not allow of any certainty of dissection or description. There was no clavicular origin.

The manubrial portion of the muscle, which has the greatest thickness, is inserted highest into the ridge running upwards from the deltoid trochanter; its inserted portion is, moreover, continuous with fascia covering the outer tuberosity of the humerus. A deeper layer of the same portion finds insertion a little to the inner side of the former, and is continuous, through the intervention of tendon, with the terminal portion of the rest of the muscle-which, in its turn, communicates at insertion with the lower part of the more superficial layer of the manubrial division, forming thus a shut sac, having the concavity upwards.

The lowest part of the tendon of insertion, which is thicker than the rest, owing to the approximation and fusion together of the walls of the above-described sac, is continued downwards to join the common tendon of insertion of the biceps and clavicular division of the deltoid.

Pectoralis minor.-A narrow, but very distinctly defined muscle, quite separable from the superjacent pectoralis major, though only differentiated from it by the intervention of cellular tissue, and not by any fascial stratum. It has an origin from the sternum, tendinous above and fleshy below, at about the level of the articulation of the fourth, fifth, and sixth costal cartilages with this bone. It then passes across the axillary space, running parallel with the subclavius, to join the upper part of the tendon of insertion of the pectoralis major (that part, namely, in which the deeper layer of the manubrial division of this muscle terminates)-which portion of the tendon is also continued over the shoulder, covering the tendon of origin of the biceps, and the tuberosities of the humerus.

Coraco-brachialis.- Is a single muscle, not complicated by any attachment to, or fusion with, the biceps. It is represented by the "long variety" of Wood only. Origin is taken from the superior extremity, and from along the inner edge of the coracoid process of the scapula, by a strong tendon, which, at the level of the inner tuberosity of the humerus, joins the body of the muscle-a few fibres, derived from the upper edge of the subscapularis, passing over it at this spot to their insertion at the above tuberosity. The muscle terminates at the inner supracondyloid ridge, its fibres being inserted into both the

${ }^{1}$ Op. cit. pp. 6 \& 7 , and pl. ii. fig. 1, pl. iii. fig. 1.

${ }^{2}$ Loc. cit. p. $296 . \quad{ }^{3}$ Op.cit. pl. 254. fig. 2, and pl. 255.

VOL. XXVI. 
anterior and posterior edges of the condyloid foramen; these diverge, however, at the internal edge, so as to leave a fissure for the passage of the median vessels and nerves. A similar arrangement has been already described by me as existing in Dasypus.

On the left side of the animal I found what may be regarded as an indication of the "short variety" (Wood), in the shape of a thin, flat muscular slip, which communicated with the posterior surface of the muscle by a delicate aponeurotically expanded tendon, which in part was inserted by a thin tendon into the lower portion of the inner tuberosity, in part communicated with the uppermost of the inserted fibres of the subscapularis by a thin expanded aponeurosis, which ran along immediately in front of the terminal portion of the bulk of this muscle.

This muscle has, according to Rapp, in $M$. tamandua, an insertion of considerable extent above the inner condyle of the humerus. It appears, also, to communicate with the short head of the biceps, since this author mentions the "common tendon" of these two muscles ${ }^{1}$.

Pouchet, in his monograph upon the Great Anteater, describes and figures the "long" variety only of the coraco-brachialis, which muscle is fused at origin with the short head of the biceps.

Biceps.-A single muscle, but well developed. It arises by a strong flattened tendon, from the superior edge of the glenoid cavity of the scapula, immediately external to the root of the coracoid process, being covered at its origin by the terminal portion of the supraspinatus muscle. After passing through a fairly defined "bicipital groove," it becomes fleshy, and increases gradually in breadth and thickness till it reaches the middle of the arm, after which point it as gradually tapers towards its insertion.

Upon entering the forearm, it becomes tendinous, and receives on its outer side the tendon of the clavicular portion of the deltoid, which becomes fused with it, and is finally inserted, as a strong flat tendon, into the inferior surface of the neck of the radius.

The terminal tendon has no ulnar insertion like that possessed by its homologue in Dasypus.

This muscle, it will be seen, has no connexion whatever with the coraco-brachialis in any part of its course.

Rapp mentions the possession by this muscle, in $M$. tamandua, of a third short head, derived from the humerus, which, he says, exists in many mammals ${ }^{3}$.

Brachialis anticus. - This muscle has an extent and position of origin similar to that of the supinator longus in this animal, only that it lies anterior to, and is overlapped by, the latter muscle. A few fibres arise from the inferior surface of the overhanging deltoid ridge of the humerus.

It passes into the forearm immediately behind the biceps, and becomes tendinous at about the level of the junction of the tendon of the clavicular factor of the deltoid with that of the former muscle. Its tendon is inserted into the ulna, immediately anterior

1 Op. cit. p. 47.

2 "Mémoire sur le Grand Fourmilier, par Georges Pouchet," I" livraison (Paris, 1867), pl. iii. figs. 1, 2. Ibid. 
to the coronoid process, but, as though vicariously, and as an effort compensatory for the single insertion of the biceps, sends a small offset to terminate at the radius, immediately below the tendon of the latter muscle.

This muscle is, according to Rapp ${ }^{1}$, wanting in the Tamandua. Meckel states that, in the Platypus, it is inserted into the radius alone by a broad tendon. In the Anteater it is fused, he says, with the "elbow-head" of the biceps".

The brachialis anticus is inserted, according to Pouchet, into the ulna only, in $M$. $j u$ bata. This muscle, he says, "se comporte avec la longue portion du biceps comme le fait la courte portion unie au coraco-brachial" ${ }^{3}$.

Triceps.-This muscle may be described as composed of four factors or elements, which are as follow :-

1. External head.-Arises from the posterior portion of the "anatomical neck" of the humerus, partly fleshy, partly tendinous, in the space intervening between the outer tuberosity and the head of the bone, overlapping here the combined origin of the preceding muscle and the supinator longus. It takes origin, too, from the space included between the articular head of the bone and the inner tuberosity, fusing here with the highest fibres of origin of the internal factor of the muscle. Halfway down it receives on its anterior free edge part of the tendon of the most posterior, or scapular, division of the deltoid. It is finally inserted into the external aspect of the long olecranon process of the ulna, fusing posteriorly, in the lower third of its course, with the anterior of the two scapular divisions of the muscle. Its anterior free edge is continuous with strong fascia covering the outer aspect of the arm.

2. Internal head.-This portion of the muscle takes origin from the whole posterior surface of the humerus, and from the posterior edge of the supracondyloid ridge, nearly as far as the inner condyle. It is crossed, at the junction of its upper with its middle third, by the tendon of the latissimus dorsi, and is finally inserted into the posterior part of the olecranon, fusing in front with the epitrochleo-anconeus and part of the flexor profundus, and behind with the offset to the elbow, derived from the latissimus dorsi (the dorso-épitrochlien).

3. Anterior scapular division. This, which appears to answer to the "long" head of human-anatomy nomenclature, is by far the largest element of the muscle. It arises from the anterior and middle thirds of the axillary border of the scapula, being overlapped at the first half of its origin by the teres minor. It is inserted into the whole of the posterior aspect of the olecranon, the outermost portion of its tendon occupying a kind of fossa at the back of the above process. At the junction of its superior with its inferior half, it is joined anteriorly by the external humeral head, posteriorly by the posterior scapular division, next to be described. On looking at this factor of the muscle from the inner side of the arm, it will be setn to be made up of two portions, the posterior of which receives into its anterior concave and semitendinous margin the posterior convex edge of the front portion.

4. Posterior scapular division.--Arises from nearly the whole extent of the posterior

$$
\text { Op. cit. p.48, = Op. cit. p.525. } \quad \text { Op. cit. p. 10; see, too, pl. iii. }
$$


third of the axillary costa of the scapula, and soon joins the latissimus dorsi, at the point where this latter gives off the dorso-épitrochlien detachment for the elbow.

If this factor of the triceps be regarded from the outer aspect of the arm, it will appear to be joined at the middle third of its hinder margin by the latissimus dorsi as this muscle passes up towards its insertion. On surveying it, however, from the inner side, the latter muscle, just before it becomes tendinous, will be seen in intimate relation with the inner face of its middle third.

The teres major, as already described, is, at its origin, completely fused with this division of the triceps. Prof. Humphry, in his description of the triceps $^{1}$, states that this factor is "confluent, to some extent, with the latissimus dorsi."

Rapp, in the course of his description of the muscles of $M$. tamandua, remarks ${ }^{2}$, that, besides the triceps, there is a longer muscle, which is, moreover, much thicker than the foregoing, and is partly covered by it. It springs from the scapula, in close company with the teres major, and is inserted into the olecranon. A portion of its tendon passes over to the fascia of the forearm, "die er spannen kann."

Pouchet describes ${ }^{3}$ a similar muscle, as present in the Great Anteater, under the name of "accessoire interne" (of the triceps), which he regards as synonymous with a muscle represented in one of Cuvier's plates of the myology of the Tamandua (op. cit. pl. 261. fig. 1), under the following designation :- "Triceps, portion allant au tendon du grand dorsal, dit quatrième extenseur."

This muscle appears, from Pouchet's figures, to be the dorso-épitrochlien, reinforced by a scapular contingent, since some of its fibres are continuous above with the latissimus dorsi, while its termination is at the elbow. This author, however, regards it as "un organe qu'on pourrait à un autre point de vue rattacher au système des muscles pouciers."

Epitrochleo-anconeus.-This muscle, which is represented by Cuvier as a division of the internal humeral factor of the biceps ${ }^{4}$, is very fairly developed. It arises from the strong tubercle in which the supracondyloid ridge ends, immediately above the inner condyle of the humerus, just posterior to the origin of the pronator teres-and terminates at the hamular projection of the olecranon, becoming first blended with the inner humeral factor of the triceps, and with the ulnar head of origin of the flexor profundus. It has the usual relation to the ulnar nerve. Cuvier represents it as too broad at its origin. Prof. Humphry describes this muscle ${ }^{5}$, under the name of anconeus internus, as an element (which it certainly is) of the triceps; and mentions, in a foot-note, that it is synonymous with the epitrochleo-anconeus, "found not unfrequently in the human subject." Rapp describes this muscle, independently of the triceps, as occurring in the Tamandua, under the name of "anconeus parvus" ".

A similar muscle is described by Pouchet ${ }^{7}$ as a factor of the triceps, under the designation of "vaste interne." It is, according to him, "très-court et forme le pendant de l'anconé." It, moreover, " cache en partie le fléchisseur commune des doigts, il en est

1 Loc. cit. p. 301.

4 Op. cit. pl. 256. fig. 5.

7 Op. cit. p. 11, and pl. iii. fig. 1.
${ }^{2}$ Op. cit. p. 48.

${ }^{5}$ Loc. cit. p. 301.
${ }^{3}$ Op. cit. p. 12, and pl. iii. fig. 1.

- Op. cit. p. 48. 
séparé par le nerf cubital." This muscle, moreover, sends upwards from its posterior part a peculiar offset, "gros comme le doigt environ," which covers the ulnar nerve, and runs parallel with it. It then bends towards the inner border of the humerus, in its passage across the brachial vessels, and, at about the middle of the arm, is suddenly continued as a delicate tendon, which spreads out and fixes itself upon the surface of the tendon of the short portion of the biceps. More details of the comparative anatomy of the epitrochleo-anconeus will be found in my paper on Dasypus sexcinctus.

Pronator teres.-A strong, well-developed muscle, arising from the upper portion of the inner border of the internal condyle, immediately above the origin of the extensor carpi radialis. It gradually broadens outwards towards its insertion into the distal half of the radius, along the strong external or dorsal ridge of this bone.

This muscle has a great similarity to its homologue in Dasypus, and, like it, does not derive any of its origin from the coronoid process of the ulna ${ }^{1}$.

Supinator brevis.-This muscle, as in Dasypus, had only its humeral origin; it had, however, proportionally a much better development. It was inserted along the outer, or dorsal, ridge of the radius, for fully half the length of the bone, but stopped short a little in advance of the posterior portion of the insertion of the preceding muscle.

According to M. Pouchet's description and figure, this muscle in M. jubata retains only its humeral origin ${ }^{2}$.

Supinator longus.-This muscle, which is absent in Dasypus, is very well represented in the forearm of the Orycteropus. It has a very extensive origin, from nearly the whole extent of the posterior surface of the humerus, in the middle line, beginning as high up as the neck of the bone, and terminating upon the "supinator ridge," soon after the commencement of this latter. It covers at its origin the whole extent of origin of the brachialis anticus, and is, in turn, at its origin, covered by the external head of the triceps, and, at its lowest part, by the fibres of origin of the extensor carpi radialis.

The muscle, having started upon its course, narrows considerably, but preserves a uniform breadth and uniform character, as a flat slip of tolerable thickness, till it reaches its insertion along the distal extremity of the radius, the middle portion being inserted by a tendon into the strong tubercle in which the dorsal ${ }^{3}$ ridge terminates, while the lateral portions are lost in a kind of aponeurosis, which covers the tendons of the principal flexors as they pass into the region of the carpus, and is also extended as a kind of fascia over the dorsum of the wrist. The outer half, moreover, of its terminal portion is fused with the annular ligament, which bridges over the three tendons of the extensor communis as they pass on to the dorsum of the carpus. This termination is very well represented by Cuvier in one of his plates ${ }^{4}$.

The presence, merely, of the supinator longus in M. tamandua is mentioned in Rapp's monograph; but Pouchet makes no reference to it in his work upon the Great Anteater. According to Meckel $^{5}$, this muscle has a very great development in the Aï, and is, in

1 Dr. Macalister "On the Nature of the Coronoid Portion of the Pronator Radii Teres," Journ. of Anat. and Phys. 2nd ser. (Cambr. 1867), vol. i. p. $9 . \quad 2$ Op. cit. p. 19, and pl. ii. fig. 3.

3 By the dorsum of the radius, I mean that surface which lies uppermost when the forearm is fully pronated.

op. cit. pl. 254. fig. 2.

${ }^{5}$ Op. cit. p. 534. 
this species of Sloth, as well as in the Anteater, differentiable into two layers-an upper, the longest, and a lower, the shorter portion.

Extensor carpi radialis.-Arises fleshy from the supinator ridge, immediately below the lowest fibres of origin of the supinator longus, and is overlapped at the lowest half of its origin by the commencement of the extensor communis digitorum. After running for about two-thirds of its course, the muscle crosses the radius, and lies in a wide shallow groove between the external edge of the bone and the mesial ridge, just in front of the lowest point of insertion of the pronator teres. Here, too, the muscle becomes tendinous, and is crossed by the tendon of the extensor ossis metacarpi pollicis.

The muscle, instead of having only one tendon (as in the specimen described by Prof. Humphry ${ }^{1}$, has two distinct well-developed tendons, of nearly equal size, the outer. most being slightly the broadest. They are inserted into the radial sides of the bases of the metacarpals of the index and middle digits respectively.

There is a slight indication of bifidity in the fleshy portion of the muscle, before it becomes tendinous.

What may be regarded as the main tendon is continued into that branch which goes to the middle digit. This, taken in conjunction with the presence of the "brevior" branch (of human-anatomy nomenclature) only, in Prof. Humphry's specimen, may indicate that the "longior" element is of secondary development.

According to $\mathrm{Meckel}^{2}$, in the Aï, Anteater, and Armadillo this muscle is single at its origin, but eventually splits into two bellies, each of which has a proper tendon of attachment to the two first metacarpals. In the Marmot, Porcupine, Beaver, Agouti, and certain other Rodents the muscle is double for the whole of its length.

Among Marsupials, according to the above anatomist, the tendon of this muscle, in the Kangaroo, splits into two divisions, the smaller of which goes to the metacarpal of the index. In Didelphys, on the contrary, this muscle is entirely in two divisions, which terminate respectively at the second and third metacarpals.

Extensor ossis metacarpi pollicis.-Arises from the lower two-thirds of the strong inner ridge of the ulna, and from the space included between this and the radial border of the bone-also from the interosseous membrane, and from the neck of the radius, close to the proximal half of the inserted portion of the supinator brevis. The muscle passes over a shallow groove in the outer half of the distal end of the radius, where it becomes tendinous, the tendon overlying those of the extensor carpi radialis, and being overlain in turn by the terminal expansion of the supinator longus over the wrist. It terminates finally on the dorsum of the trapezium, which bone, though not a supporter of the index, is strongly attached to its radial side by a ligament.

There is no indication in the tendon of this muscle of that bifidity which takes place in its serial homologue the tibialis anticus. In Dasypus, too, as I have described, the tendon of this muscle is single.

The tendon of this muscle in the Great Anteater, which is also single, is principally inserted into the trapezium; but "quelques fibres," says Pouchet ${ }^{3}$, "tendineuses gag-

${ }^{1}$ Loc. cit. p. $306 . \quad{ }^{2}$ Op. cit. p. $538 . \quad{ }^{3}$ Op. cit. p. 23 ; see, too, pl. ii. figs. 1 and 3. 
nent seules la tête du premier métacarpien. Le muscle ne peut donc agir directement sur le pouce; il est, avant tout, un muscle de la station."

May not the above-described insertion of the terminal tendon principally into the trapezium, while but few of its fibres pass to the metacarpal of a pollex which, though somewhat feeble, must still be ranked among the range of digits ${ }^{1}$, either be looked upon as the soon-to-be-cast-off appendage of an already useless member, or be regarded in the light of a preparation for a yet more rudimentary, or rather decadent, condition of the pollex, such as exists in the Orycteropus, in which animal the sole representatives of this digit are two difficult-to-be-discovered, seemingly insignificant ossicles ${ }^{2}$ ?

In the Guineapig, in which the pollex is absent, the tendon of the extensor ossis metacarpi pollicis, according to Mr. Mivart and Dr. Murie ${ }^{3}$, "runs on to the base of the metacarpal of the index, though mainly inserted into the rudimentary trapezium."

According to Prof. Huxley, while the tendon only of this muscle is divided in the Gorilla, Orang, and Gibbon, this division involves the muscle itself in the Chimpanzee ${ }^{4}$.

Soemmering has noticed in man ${ }^{5}$, besides the simple splitting of the tendon, the actual division of the muscle itself. Theile has recorded that this muscle has sometimes been observed in man to be divided into two parts along its whole extent ${ }^{6}$.

Extensores primi et secundi internodii pollicis.-These muscles are, as might be expected, absent.

Extensor indicis.-Arises from the middle third of the strong internal ridge, or margin, of the ulna, immediately anterior to the insertion of the external portion of the triceps, lying, also, immediately to the outer side of the extensor ossis metacarpi pollicis, at the origin of this latter.

After this, it rapidly narrows, and its tendon, on reaching the articulation of the radius and ulna, runs under a ligamentous bridge stretching between the adjacent corners of the extremities of these bones, and passes on to the dorsum of the hand, underneath the three branches of the common extensor tendon. At a short distance from its termination, it divides into two slips, which are inserted into the bases of the proximal phalanges of the index and "middle" digit respectively.

Extensor communis digitorum.-Arises from the lower part of the "supinator ridge" of the humerus, overlapping here the lower half of the origin of the extensor carpi radialisalso from the tubercle upon the external condyle, which gives origin to the supinator brevis, being fused at this point of origin with the extensores annularis and minimi digiti.

Shortly before it arrives at the distal extremity of the radius, the muscle divides into two bellies, which become tendinous on passing under the annular ligament common to them and to the tendon of the extensor indicis. The ulnar tendon, at the carpo-metacarpal

x Pouchet remarks, in a kind of preface or introduction, op. cit. p. 3, “Le premier doigt est grêle, un peu détaché des antres, mobile. On peut lui donner le nom de pouce."

${ }^{2}$ Cuvier says, "Le premier os du second rang [of the carpus] est un trapèze auquel s'attachent deux très-petits os, seuls vestiges du pouce."-Ossemens Fossiles (nouvelle édit. Paris, 1823), tome v. p. 135.

3 " On the Anatomy of the Crested Agouti," Proc. Zool. Soc. June 1866, p. 404.

- Lect. Coll. Surg. See Med. Times and Gazette, 1864.

- De Corp. Humani Fabr. vol. iii. p. 239.

- Encyclop. Anat. (Paris, 1843), tome iii. p. 232. 
articulation of the foot, splits into two branches, which terminate at the ungual phalanges of the "fifth" and "fourth" digits respectively. The radial tendon also splits into two branches, at a similar articulation to that at which the ulnar divides, which terminate respectively at the ungual phalanges of the index and " middle" digits.

The radial branch of the muscle, moreover, detaches from its ulnar side, on becoming tendinous, a somewhat slight tendinous slip, which passes to a short transverse band, by which the ulnar and radial tendons communicate before they each split into two branches.

The somewhat slender tendon of the extensor indicis passes beneath the tendons of the extensor communis as they run under the bridge formed by the annular ligament; and the radial branch of the extensor annularis, which passes to the middle digit, appears to communicate with the inferior surface of the ulnar tendon of the extensor communis.

Cuvier represents this muscle as giving off, upon its emergence from under the terminal expansion of the supinator longus, three equal-sized tendons, which pass to the index, "middle," and "annularis" digits respectively".

In Prof. Humphry's specimen ${ }^{2}$ there were "four tendons derived from two bundles of muscle," \&c.

Extensor annularis.-A.rises from the upper portion of the external condyle of the humerus, immediately below, and in conjunction with, the common extensor. It then runs between this muscle and the extensor minimi digiti as far as the beginning of the carpus, and becomes tendinous at the level of the carpo-metacarpal joint of the digit from which it derives its name, and at this point runs under a delicate ligamentous bridge.

The tendon then passes under the ulnar division of the common extensor tendon, dividing here into two branches, one of which passes to the ulnar side of the base of the proximal phalanx of the third ("middle") digit; while the other courses along the ulnar side of the fourth ("annularis") digit, and, after sending downwards an offset at the level of the base of the proximal phalanx, which is joined by an interosseus muscle occupying the intermetacarpal space between the fifth and the above digit, is continued onwards to the base of the distal phalanx.

Cuvier represents ${ }^{3}$ the tendon of this muscle as dividing into two branches, the radial of which passes beneath the ulnar division of the common extensor tendon to the ulnar side of the "middle" digit; while the ulnar branch runs to the "fifth," and not to the "fourth" digit.

Neither the branch to the "middle" digit nor the communication with the interosseus appears to have existed in Prof. Humphry's specimen".

I have described a muscle similar to the above as present in Dasypus sexcinctus.

Extensor digiti minimi.-A fusiform muscle, which arises from the external face of the outer tuberosity of the humerus, immediately below the origin of the extensor annularis, and above that of the extensor carpi ulnaris, with which muscle it is fused for the first half of its course. It does not become tendinous till it nearly reaches the extremity of the ulna; here its tendon passes to the radial side of a tubercle which lies at about the

\footnotetext{
${ }^{1}$ Anat. Comp. pl. 254. fig. 2.

Op. cit. ibid.

2 Loc. cit. p. 307 .

4 Loc. cit. p. 307.
} 
middle of the distal margin of the bone, and is here bridged over by a distinct, but very delicate ligament, which is attached to the above tubercle. Near its termination the tendon broadens, and, crossing over that of the extensor carpi ulnaris, is inserted, partly into the base of the proximal phalanx of the fifth digit, partly into a sesamoid ossicle situated at the ulnar side of this phalanx, and partly, but principally, into the ulnar side of the distal phalanx of the same digit.

I did not find any offset to the fourth digit, as described by Prof. Humphry ${ }^{1}$, and represented by Cuvier in one of his figures ${ }^{2}$ as the principal branch of the extensor minimi digiti.

Such an offset has, however, been found by Church in the Orang ${ }^{3}$; and Henle, moreover, describes ${ }^{4}$ the tendon as sometimes splitting in Man, the two divisions either passing separately to the fourth and fifth digits, or both terminating at the latter digit, as happens, according to Meckel, in the Ornithorhynchus ${ }^{5}$.

In Hyrax Capensis this muscle was found by Dr. Murie and Mr. Mivart dividing early into two slips, which terminated separately at the fourth and fifth digits.

In Dasyprocta cristata, according to the same authorities, the tendon alone was split, but its branches had a similar termination ${ }^{6}$.

Extensor carpi ulnaris. - Starts from the external condyle of the humerus, immediately below the preceding muscle, and for the first half of its course is intimately fused with it. On reaching the distal extremity of the ulna, it becomes tendinous, the strong flat tendon lying to the ulnar side of the tuberosity mentioned in the description of the preceding muscle. Its tendon divides into two branches, one of which is inserted into the ulnar side of the base of the metacarpal of the fourth digit, the other into the inferior face of the like factor of the fifth.

The former of these branches has been well represented by Cuvier ${ }^{7}$.

In the Anteater, according to $\mathrm{Meckel}^{8}$, this muscle goes to the rudiments of the fourth and fifth digits.

Flexor carpi ulnaris.-This muscle may be described as made up of two factors :-a small, or deep, portion, which arises by a very distinct rounded tendon from the middle of the inner edge of the ulna; this tendon, running between the flexor profundus and the more superficial factor of the flexor unaris, after gradually widening, becomes muscular at about the distal fourth of the bone; and the muscle, also gradually widening, is finally inserted all along the stem of the long, style-shaped os pisiforme ${ }^{9}$ : the bulk of the muscle arises from the whole inner edge of the ulna, and from the olecranon, by a broad aponeurotic tendon, to which the flexor profundus is closely adherent. Muscular fibres are not added to this aponeurosis until it attains the middle of the forearm. At its termination this factor has two distinct insertions-the outer into the free extremity of the

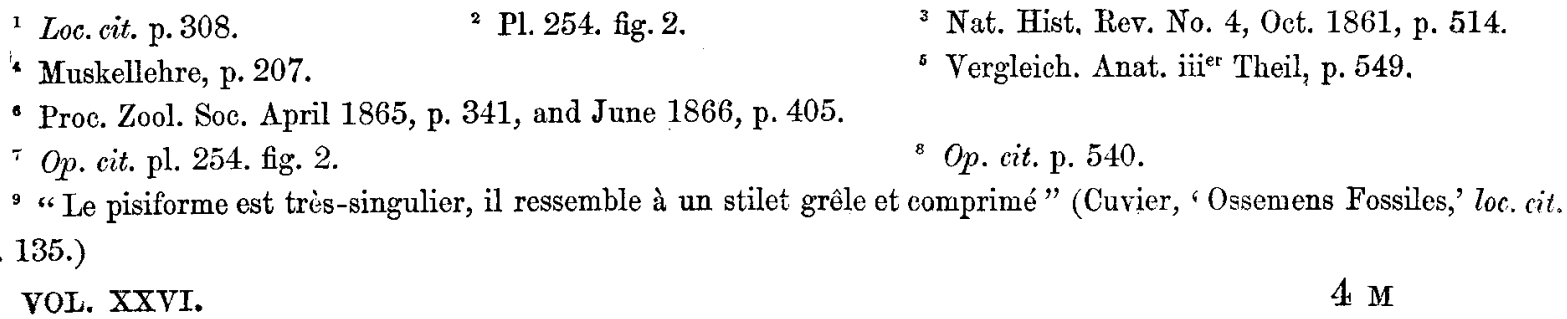


pisiform bone, besides being continued on, as a strong tendon, to the palmar process of the unciform bone, while the inner, or ulnar, insertion is by tendon into the base of the proximal phalanx of the fifth digit, some fibres, too, taking origin from the tendon or ligament described above as passing from the pisiform to the unciform bone.

This muscle, according to $\mathrm{Meckel}^{1}$, is enormously developed in the Two-toed Anteater, and is, moreover, divided into four parts. The opinion that these are all factors of one muscle (the fexor ulnaris) appears to be supported by the fact of their coexistence with a complete set of the muscles of the hand. Further on, however, Meckel regards one of these elements as the palmaris longus.

Flexor carpi radialis.-Arises from the outer edge of the external condyle of the humerus, from a tubercle immediately below that which gives origin to the pronator teres. It is inserted by a strong flattened tendon into the palmar aspect of the base of the metacarpal of the index, a sesamoid bone intervening at the insertion, and partly into the inferior surface of the styloid process of the radius.

The tendon of this muscle in Dasypus sexcinctus, as I have already described, terminates at the trapezio-trapezoid bone, after running through a groove in the scaphoid.

The annular ligament of the palm is very strong. It is attached, on one side, to the downward-looking process of the unciform bone, a flattened oval sesamoid being imbedded in it not far from this attachment, and, on the other side, into a sesamoid bone (rudiment of the pollex?) lying close to the radial edge of the trapezium.

From the anterior edge of the first-described sesamoid passes a short rounded tendon, or ligament, to the root of the branch given off to the fourth digit from the common deep flexor tendon.

Flexor digitorum sublimis.-With this muscle is combined, as in Dasypus, the palmaris longus, both functionally and homologically. It arises from the lowest of those factors of the deep flexor which take origin from the inner condyle of the humerus, at about midway between the origin and insertion of the muscle, by a tendon which runs back in the substance of this factor for some distance. At the carpo-metacarpal joint, after passing over the strong annular ligament, it becomes tendinous, and the tendon almost immediately divides into four equal-sized branches, destined one for each digit. Each of these tendons seems to be separable into two layers, the external of which, at the metacarpo-phalangeal articulation of its proper digit, is prolonged over the deeper layer, to join the projecting margin, on either side, of a large grooved sesamoid which lies at the above articulation-and is, moreover, inserted all along each side of the several phalanges belonging to its digit, so as to form a kind of sheath for the flexor profundus. The inner layer, which appears to answer to a "perforated tendon" (in human-anatomy language), at about the middle of the proximal phalanx of its proper digit splits to allow of the passage of the tendon of the flexor profundus, but joins again to run beneath the "perforating" tendon and be finally inserted at the base of the second phalanx, through the medium of a sesamoid bone.

The tendon which passed to the "middle" digit was joined, on its inferior aspect at origin, by the thin tendinous termination of a flat and delicate muscular slip which,

$$
{ }^{1} \text { Op. cit. pp. 542, } 545 \text {. }
$$


passing under the annular ligament, gained its origin at the middle of the common tendon of the flexor profundus, at the radial side of the most internal lumbricalis.

The flexor sublimis is absent, according to Rapp, in the Tamandua, as is also a proper palmaris longus'. This author, however, describes a tensor ("Spannmuskel") of the annular ligament, which, at first sight, he says, might be taken for the latter muscle, but which passes under the ligannentum carpi volare proprium, as under a bridge, and is attached to the annular ligament. Before, however, its tendon passes under the volar ligament, it is joined by a muscle which takes origin from the olecranon and the greater part of the length of the ulna?

Flexor profundus digitorum.-A hugely developed muscle, having a very large and varied extent of origin. It is made up of several factors of irregular size. One of these arises from the posterior two-thirds of the inner margin of the ulna, and from its palmar aspect for a like extent, the remaining third of the inner margin of the bone being occupied by the fibres of origin of the flexor carpi ulnaris. The above factor, when it has run about two-thirds of its course, is joined by another, which takes origin by a strong tendon from a fossa on the inferior aspect of the humerus, situated between the external condyle and the trochlea, and which also affords origin to another slip, which joins the expanded common tendon in the middle line, lying betwixt the termination of the two principal factors of the muscle.

The greater part of the ulnar division, after being joined by a slip of inconsiderable size, which takes origin from the radius posterior to the insertion of the pronator teres, passes to the radial side of the expansion of the common tendon of the muscle, the ulnar side of this tendon being joined by a small remaining portion of the ulnar factor, and by that part which arises from the inner condyle of the humerus. This latter consists of two slips, which arise below the origin of the flexor carpi radialis, and the ulnar side of which, on completing half of its course, gives origin to the flexor sublimis. This condyloid factor of the muscle lies more superficial throughout its course to that portion which takes origin from the radius and ulna.

At the posterior border of the carpus all these factors join a large tendinous expansion, which has not, as in Dasypus, any sesamoid bone developed in its substance. This expansion, after affording origin to the lumbricales, divides into four equal-sized tendons, which pass as "perforating" flexors to the terminal phalanges of the four digits, having, moreover, at the junction of the middle with the distal phalanx of their respective digits, an indication of bifidity, but becoming single again before insertion.

The sheath of each of these tendons is, at about the middle of the proximal, and the proximal end of the middle phalanx of its proper digit, strengthened by a broad ligamentous band or arch, which passes from one side of the phalanx to the other, over the subjacent tendon. "Retinacula" also pass from the inferior surface of the "perforating" to that portion of the "perforated" tendon which, after splitting, unites again under the former tendon.

To the upper surface of the origin of the tendon destined for the fourth ("annularis")

${ }^{1}$ Op. cit. p. $48 . \quad 2$ Op. cit. p. 49. 
digit passes a short, but strong, rounded tendon or ligament from the anterior edge of the sesamoid included in the annular ligament.

Neither Meckel, Rapp, nor Pouchet makes any mention of the presence of a sesamoid in the tendinous expansion of the deep flexor in the species of Anteater which they severally describe. Such an ossicle is present, however, in Chlamydophorus, as well as in Dasypus sexcinctus, as I have mentioned in my paper on the latter species of Armadillo.

Pronator quadratus. - This muscle, which is described as "small" by Prof. Humphry, was very well developed and of considerable extent in the specimen which I examined. It filled the whole interosseous space of the forearm, as well as the anterior face of the radius and ulna, from the level of the insertion of the biceps and brachialis anticus to the distal extremity of the two bones.

This muscle has a great resemblance to its homologue in the Great Anteater, as represented by Pouchet in his monograph (pl. iv. fig. 3), having a strong tendon running across it obliquely at the junction of its middle with its lower third. This muscle is, moreover, described by the same author as occupying three-quarters of the extent of the forearm ${ }^{1}$.

Meckel, in his monograph upon the Two-toed Anteater, makes no mention of this muscle when describing the myology of the animal ${ }^{2}$.

According to Rapp ${ }^{3}$, the pronator quadratus is present in $M$. tamandua. Cuvier, moreover, just slightly indicates the distal extremity of the muscle in one of his plates of the myology of this animal ${ }^{4}$, but gives no representation of it in his drawings of the anatomy of the two-toed species.

No indication of the presence of this muscle is given by the same anatomist in his plates of the Three-toed Sloth ("Aï").

I have already described this muscle as absent in Dasypus sexcinctus, and have, moreover, referred to Meckel's description of its peculiarities in the Aï.

Lumbricales.-Are four in number, and are well developed. One passes to the radial side of each digit, being inserted into its proximal phalanx. In the case of the index, " middle," and "fourth" digits, this attachment is effected through the medium of a tendon; but the muscle destined for the "little" finger continues fleshy up to its insertion, where, moreover, it is broader than at its origin. These muscles do not appear to have any connexion with the sheaths of the extensor tendons. The three outermost rise together, but quite distinct, from the expanded common tendon of the flexor profundus. That passing to the "little" finger rises from the same tendon, but a little more posteriorly; so that a few of its hindermost fibres of origin fuse with the terminal fibres of the enormous muscular mass which rises from the inner condyle of the humerus, and from which is given off the muscle which is the representative of the flexor sublimis and palmaris longus. Close to the radial side of the last-described lumbricalis, rises a thin flat slip from the tendon of the deep flexor, which passes under the annular ligament to terminate at the inferior surface of the flexor sublimis.

The lumbricales are very fairly represented by Cuvier in one of his plates ${ }^{5}$.

Abductor minimi digiti.-A small muscle. It arises from the palmar process of the

${ }^{1}$ Op. cit. p. 17.

s Op. cit. p. 48.
2 Deutscher Archiv, Vter Band (Halle und Berlin, 1819).

- Op. cit. pl. 263. fig. 2.
' Op. cit. pl. 256 fig. 5. 
unciform bone, and is inserted, a sesamoid ossicle intervening, into the base of the proximal phalanx of the "little" digit. Some fibres, too, join the tendon of the innermost of the superficial interossei.

Interossei.-These muscles, to avoid confusion as much as possible, are, I think, better divided into superficial and deep, than into palmar and dorsal interossei. There are only two superficial muscles, which cross each other like the upper arms of an $\mathrm{X}$ and seem to correspond to two out of the three muscles described by Prof. Humphry as "palmar" interossei".

The one which passes to the "little" digit arises from the ulnar half of the palmar ligament, immediately anterior to the front margin of the unciform bone. It is a fanshaped muscle; and its fibres radiate towards a flat tendon, which, passing along the radial side of the little digit, joins that branch of the extensor communis which is sent to this digit. On becoming tendinous it is joined by a slender offset from the abductor minimi digiti.

The other superficial interosseus is covered by, and arises a little in advance of, the preceding, from the palmar ligament at the neighbouring parts of the bases of the metacarpals of the third and fourth digits. After widening a little from its origin, it again gradually contracts, and joins, through the medium of its tendon, the tendon of the deep interosseus which passes to the ulnar side of the index.

When these two muscles act in concert, they must strongly adduct the outermost and innermost digits towards the middle line of the hand.

Deep interossei.-To facilitate description, it had better first be stated that each digit has a strong ligament, oblique in direction, attached, at one extremity, to the ulnar side of the base of its metacarpal, at the other, after previously forking, into the sesamoid at the base of its proximal phalanx. The deep interossei have great extent of origin from these ligaments, which may conveniently be termed "metacarpal" ligaments, and from eacb of which a pair of the above muscles arises, those taking origin from the radial sides passing to the radial, those from the ulnar passing to the ulnar sides of their corresponding digits.

The radial interosseus of the index has two heads of origin-one, fusiform, by a distinct tendon, from the anterior edge, palmad, of the scaphoid, the other from the radial side of the metacarpal ligament of the index. These, after junction, become tendinous; and their tendon joins the branch of the extensor communis sent to the index. The ulnar interosseus of this digit arises from the inner side of its metacarpal ligament, and, after becoming tendinous, sends an offset to the sesamoid bone, is joined by the radial of the two superficial interossei, and passes to the expansion of the common extensor tendon over the proximal phalanx. This muscle may, I think, be termed conveniently, if not homologically, "abductor indicis." The " middle" and "fourth" digits have each a deep interosseus on either side. From the obliquity of the metacarpal ligaments of the index and two succeeding digits, the muscles on the radial sides seem to have a much more strictly palmar origin than their fellows on the ulnar sides--these latter being almost hidden, when the digits are closely approximated, in the intermetacarpal spaces.

I Loc. cit. p. 305. 
The radial and ulnar interossei of the "middle" and "fourth" digits, after taking origin from the corresponding sides of the ligaments of their respective metacarpals, sent each an offset to the sesamoid at the base of the proximal phalanx of its proper digit, and finally joined the extensor tendon above. The radial interosseus, however, of the " middle" digit had two heads of origin, one from the ulnar side of the metacarpal ligament of the index, the other from the radial side of the ligament of its proper metacarpal.

Each digit, it will be seen, has an interosseous abductor and adductor, the index possessing, moreover, an accessory adductor on its ulnar side.

Lower Extremity. Gluteus maximus.-A very broad and flat muscle, but of no great thickness. It took origin from the crest of the ilium, and from what, for want of a better term, I must call the "sacral aponeurosis." Its lowest fibres of origin are overlapped by the superior edge of the strongly developed biceps; which fact may have led Prof. Humphry to describe the gluteus as continued down to the heel ${ }^{1}$, while in reality it is the biceps which undergoes so considerable an extension, a point which Cuvier has very clearly and correctly indicated in one of his plates ${ }^{2}$.

The only actual point of insertion of the muscle is the strongly developed third trochanter of the femur, to which the gluteus is attached by a flat tendon, developed early along its inferior edge. The anterior portion of the muscle, moreover, is lost in fascia, in which the tensor fascice terminates, and which is also continuous with the tendon of the biceps.

Tensor fascia femoris.-Is a distinct muscle ${ }^{3}$, which may be, however, but a differentiated layer of the preceding. It takes origin from the homologue of the anterior superior spine of the ilium, being almost completely overlapped by the anterior portion of the gluteus maximus, and is continued into the fascia in which part of the preceding muscle is lost, and with which the tendon of the biceps communicates, and which is also attached to the outer side of the femur from the third trochanter to the condyle. Prof. Humphry evidently regards this muscle as but a differentiated portion of the gluteus.

The editor of the second edition of Cuvier's 'Leçons,' in the following parenthetical remark, may possibly be alluding to the tensor fasciae :- "Dans tous les mammifères, le fascia lata a un muscle assez fort qui se sépare difficilement du grand fessier."

Gluteus medius.-A well-developed muscle, taking origin from the outer face of the ilium and adjoining portion of the sacrum. The greater part is inserted into the outer and inferior aspect of the great trochanter, covering the terminal portions of the gluteus minimus and pyriformis, the rounded anterior edge becoming intimately connected with that of the former of these two muscles; while a thin factor, which is rolled over its posterior edge, is inserted along the outer and inferior edge of the femur, nearly as far as the third trochanter.

Cuvier gives, in one of his plates ${ }^{5}$, a very good representation of the two portions of the gluteus medius.

1 Loc. cit. p. 311.

4 Vol. i. p. 521.
$=$ Op. cit. pl. 254. fig. 2.

Pl. 256. fig. 1, op. cit.
${ }^{3}$ Cuvier, pl. 256. fig. 1 . 
Gluteus minimus.-Arises from the outer surface of the ilium, covered by the upper twothirds of the pyriformis, and is inserted above this muscle into the upper part of the great trochanter.

Pyriformis.-A large well-developed muscle, taking origin mostly from the outer face of the ilium near its junction with the sacrum, a few of its lowermost fibres arising from the inner face of the latter bone. It is inserted by a broad strong tendon into the outer face of the external trochanter, below the termination of the gluteus minimus. For the whole of its extent, both at origin and at insertion, it is covered by the gluteus medius.

Perhaps this muscle ought to be regarded as a deeper factor of the gluteus last mentioned. A fair representation of it may be found in Cuvier's plates ${ }^{1}$.

Obturator externus. - Is a large, fleshy, fan-shaped muscle, taking origin from the anterior half of the circumference of the obturator foramen, and being inserted by a strong tendon into the digital fossa of the femur.

Obturator internus. - This muscle, which I have described as absent in Dasypus sexcinctus, is, for a great part of its extent, concealed within the pelvis; but its terminal portion may be seen emerging at the lesser sciatic notch, immediately below the representation of the lesser sacro-sciatic ligament, at which point it passes over a smoothgrooved facet and becomes tendinous, its tendon very soon fusing with that of the gemelli.

According to Cuvier ${ }^{2}$ the obturator internus arises solely from the inner aspect of the posterior branch of the ischial tuberosity.

Gemelli.-Are very well developed, and occupy their usual position in relation to the preceding muscle. They seem, however, each to have two heads of origin. The superior gemellus rises, as usual, from the posterior edge of the ischium, immediately above its "spine"-also, for a certain extent, from the inner face of the bone. It is, moreover, reinforced by a flat muscular slip which takes origin from the posterior half of the sacral edge of the large sacro-ischiatic foramen, and the tendon of which joins the first-described element of the muscle after this has become tendinous. The inferior gemellus takes origin, in part, from the free edge of the ischium below the spine of the bone, but mostly, as a large fleshy belly, from the posterior part of the tuberosity and from what may be regarded as the greater sacro-sciatic ligament.

The strong conjoined tendon of the gemelli is joined in the middle by that of the obturator internus, and then terminates in the digital fossa, above the insertion of the obturator externus.

Prof. Humphry does not appear to have found any sacral origin of these muscles in the specimen which he has described ${ }^{3}$; but Cuvier has left a short note, which M. Ad. Focillon has incorporated in a description of his plates of the Orycteropus, and which is as follows:- "Les Jumeaux viennent du Sacrum; le Jumeau postérieur (inférieur) a aussi des fibres de la tubérosité de l'Ischion."

Quadratus femoris.-My specimen agreed with that of Prof. Humphry in not possessing the above muscle. Cuvier, however, has in two of his figures ${ }^{4}$ attached to a large muscle

1 Pl. 256. fig. 3, op. cit.

2 See short note by this author, appended to the description of his plates of the anatomy of Orycteropus.

Loc. cit. p. 312.

* Op. cit. pl. 256 . figs. 1 \& 3. 
the symbol proper to the "carré de la cuisse" ; but I think that the muscle here represented must be that which I have regarded as the homologue of the "adductor minimus" of Henle, and which Cuvier has figured elsewhere ${ }^{1}$ as the "moyen adducteur."

According to $\mathrm{Meckel}^{2}$, the quadratus femoris is absent in the Anteater.

Theile ${ }^{3}$ notices the occasional absence of this muscle in Man, and further observes that "alors les jumeaux ont plus de volume." With the only instance in which Hallet found the quadratus femoris deficient in Man (out of 105 subjects examined), there was associated an unusual development of the two gemelli and obturator internus ${ }^{4}$.

On reference being made to my paper on Dasypus sexcinctus, it will be seen that while the muscle in question is in this animal exceedingly well developed, the obturator internus is absent, and the gemelli very small-the converse of Theile's and Hallet's observations being thus illustrated in a very singular manner.

Such mutual compensation, however, is by no means always to be found in animals; for in the Echidna, according to Mr. Mivart", the quadratus femoris is a "delicate muscle," though both obturator internus and gemelli are completely absent.

Ilio-psoas.-The origin of this compound muscle could not with certainty be determined, since much damage had been done to it in the evisceration, as I suppose, of the animal. It is inserted along the inner trochanter of the femur as high up as the head of the bone, and along the inner edge of its shaft for nearly the extent of its upper half.

Cuvier represents ${ }^{6}$ the iliacus muscle as being in two portions near its insertion. Prof. Humphry, however, makes no mention of any such division. The condition of this portion of the animal which I examined did not allow any verification of this point.

The former author, too, represents ${ }^{7}$ the psoas as having the lowest insertion along the femur. Now, as far as I could determine, this muscle is inserted tendinously into the trochanter alone, while the iliacus is continued fleshy along the inner edge of the shaft of the bone.

Psoas parvus ${ }^{8}$.-For a like reason to that already given in the case of the preceding

${ }^{1}$ Tab. cit. fig. 4. $\quad 2$ Op. cit. p. 586. $\quad 3$ Encyclopédie Anatomique (Paris, 1843), vol. iii. p. 279.

4 Edin. Med. and Surg. Journ. vol. Ixix. 1848, p. 20. ${ }^{5}$ Trans. Iinn. Soc. 1866, vol. xxv. p. 392.

'Op. cit. pl. 255.

s It is much to be regretted that the bulk of this muscle had not been preserved in the specimen from which my notes are derived; for its condition of development might serve to throw some light upon the probability or otherwise of the Orycteropus frequently assuming a Kangaroo-like attitude. See Rapp, op. cit. Taf. i., where one of the animals figured is represented in the erect position-the strong stout tail forming the third element of its tripodal support, and the hand drooping from the forearm in a position frequently to be witnessed in Macropus as a natural condition, and in Homo as a pathological one. Such an attitude must, I think, be greatly subserved by the muscle in question, seeing that its homologue in the Kangaroo, according to Meckel (Vergleich. Anat. p. 590), exceeds in bulk the psoas magnus by at least ten times. Prof. Humphry merely remarks that it is "large," but makes no observation as to its size in relation to that of the "great" psoas.

I have found no record, in the works which I have consulted on the subject, of the Aard-vark being known to assume the attitude in which it has been represented by Rapp.

The figure above mentioned may, after all, be but the representation in the concrete of an abstract conception formed by its author of the possible existence of marsupial affinities in the Orycteropus.

Since the above was written, I have seen, among the stuffed specimens of Bruta preserved in the British Museum, an Anteater, labelled "Tamandua tetradactla" (sic), which was placed erect upon its hind legs, the tail being curled 
muscle, the origin of this muscle could not be determined with any accuracy. It was inserted by a rounded tendon into the strongly developed ilio-pectineal tubercle ${ }^{1}$.

Pectineus.-'This muscle appears to be made up of two distinct portions, which seem to answer to the two layers into which its homologue in Man may, according to Henle? be differentiated. Cuvier, too $^{3}$, distinctly represents a like arrangement in the animal which is the subject of this description.

The first or upper portion of the muscle is strap-shaped, and takes origin from the strong ilio-pectineal tubercle, beneath that of the gracilis. It is inserted into the "linea aspera" of the femur, from below the lowest point of insertion of the iliacus to the femoral insertion of the semimembranosus. The second or lower portion is much smaller, and arises from the ilio-pectineal line, between the origin of the first factor of the muscle and that of the adductor longus. It is inserted into the lowest portion of the posterior intertrochanteric line, on the border of the digital fossa.

The arrangement of this muscle in Prof. Humphry's specimen appears to have been very different ${ }^{4}$.

Adductors.-These "adductors" proper appear to be present. They seem to answer" respectively to the longus and brevis of human-anatomy nomenclature, and to the muscle termed by Henle " minimus," - the upper portion of the great adductor, according to Theile and other anatomists.

a. The homologue of the adductor longus is a muscle of comparatively small size; it springs from the lower portion of the ilio-pectineal line and from the spine of the pubes, just below or posterior to the second or inferior division of the pectineus, being overlapped by the highest fibres of origin of the gracilis. It passes, uniform in breadth, to be inserted by a thin tendon into the linea aspera of the femur, alongside of the inserted portion of the first division of the pectineus. I could not find any special or distinct representation of this muscle in Cuvier's plates.

$\beta$. This muscle, which I am inclined to regard as homologous with the adductor brevis, is of very great size, and has an extensive origin from the remaining portion of the pubes included between the symphysis and lowest fibres of origin of the adductor longus, also from the greater part of the descending ramus of this bone, being covered partly by the gracilis, and partly by the semimembranosus. It has a lower point of insertion than any of its fellows, since it terminates on the inferior surface of the femur, diagonally between the third trochanter and a point midway between the origins of the gastrocnemii.

Cuvier gives a fair representation of this muscle, divided close to its origin and insertion $^{6}$, but letters it as the adductor brevis.

$\gamma$. The remaining muscle answers, I think, most nearly to that portion of the "great" adductor termed and figured" by Henle "adductor minimus." Cuvier, in the figures cited

\footnotetext{
round on the board which supported the specimen. The upper half of the body was bent forward at nearly a right angle with the lower part, while the fore limbs were disposed as they are in a Kangaroo.

1 “ Une apophyse pointue sur la base du pubis, et dirigée en avant, c'est-ì-dire, vers le ventre." (Cuvier, 'Ossemens Fossiles,' loc. cit. p. 136.) $\quad{ }^{2}$ Muskellehre, p. 268, and fig. $139 . \quad{ }^{3}$ Anat. Comp. pl. 256. fig. 4.

${ }^{4}$ Loc. cit. p. 310. $\quad{ }^{5}$ Op. cit. p. $270 . \quad{ }^{6}$ Op. cit. pl. 256. figs. 4 and $6 . \quad 7$ Loc. cit. fig. 140. VOL, XXVI. $4 \mathrm{~N}$
} 
above, letters this muscle as the "moyen adducteur" (the "adductor longus" of the modern English schools).

This adductor has a large fleshy origin from the ascending ramus of the ischium and from part of the triangular surface included between the obturator foramen and the tuberosity, being overlapped by the adductor muscle last described, and covered for the rest of its extent by the semimembranosus, tendinosus, and biceps. Narrowing gradually towards its termination, it is inserted, partly fleshy, partly tendinous, into a sharppointed tubercle situated on the ridge which runs down from the lesser trochanter, along the inferior surface of the femur, just superior to the combined insertions of the adductor longus and the first division of the pectineus.

The muscle which I have termed adductor longus may, after all, be only a third element of the pectineus.

Cuvier, although he has represented two adductors in his plates, has nevertheless left on record the following note, which $\mathbf{M}$. Focillon has appended to his description of these plates,- "Il n'y a qu'un adducteur."

The Aï has, according to Meckel ${ }^{1}$, four adductors, besides a pectineus of very great extent of insertion. The Anteater, also, has a large pectineus, but only a single adductor, which, however, is well developed, and formed from three heads.

Quadriceps extensor.-The rectus femoris has no peculiarities worthy of much notice. It was well developed, and took origin from the superior and posterior margins of the acetabulum, and was inserted into the superior edge of the patella in company with the vastus of either side.

The vastus externus was enormously developed. It arises from the external aspect of the femur and from the whole of its anterior surface, from as high a position as the space included between the great trochanter and the head of the bone. It is inserted into the outer edge of the patella, overlapping the rectus at its insertion.

The vastus internus is much smaller, but is so fused with the preceding muscle in the middle line, that a boundary can hardly be sharply marked between them. It arises from the inner edge of the upper half of the femur immediately below the head of the bone, and is inserted, having previously fused with the rectus, into the inner edge of the patella. The aponeurotic termination of the sartorius is intimately adherent to its upper surface.

No crureus can be differentiated from the muscle, unless the lowermost layer of the vastus externus, which arises from the anterior aspect of the femur, be reckoned as this muscle.

The patella, besides being connected with the smooth broadened-out origin of the spine of the tibia by a strong "ligamentum patellæ," is fastened to the femur by a kind of side stay, in the shape of a strong flat ligament which passes from its inferior edge to the outer aspect of the external condyle.

Sartorius.-Appears to have slipped down from its usual origin, since it arises from the strongly developed ilio-pectineal tubercle, immediately above the highest fibres of origin of the gracilis. It then passes forwards, and ends in the upper portion of the

$$
{ }^{1} \text { Op. cit. p. } 596 .
$$


terminal aponeurosis of the gracilis, besides becoming continuous with the dense fascia covering the rectus near its insertion. The sartorius is separated from the subjacent muscles by fascia, in which the internal saphenous vein runs upwards towards its termination.

Cuvier gives in his plates a very distinct representation of this muscle, which agrees with my description ${ }^{1}$. According to Prof. Humphry ${ }^{2}$, however, this muscle has no connexion with the ilium, but arises from the hindmost ribs.

The editor of the second edition of Cuvier's 'Leçons' (loc. cit. p. 518) confirms Meckel's statement (loc. cit. p. 614), that this muscle in the Aï has a femoral insertion; but states that it comes from the ilium, and not, as the latter anatomist has said, from the aponeurosis of the external oblique.

Semitendinosus.-This muscle consists of two quite distinct portions, both as regards their origin, course, and insertion. The first portion, which corresponds to the muscle of the same name in Man, is of uniform breadth, strap-shaped, and takes origin from the whole extent of the free edge of the tuberosity of the ischium, including the spine at its most posterior boundary. It passes across the thigh to be inserted into the inner layer of the aponeurotic termination of the gracilis, being covered by the lowest portion of this muscle at its insertion. When it reaches the posterior border of the gastrocnemius, the muscle receives on its inferior edge a contribution from the semimembranosus, which becomes continuous with fascia or aponeurosis extending to the calcaneum.

The second portion of the muscle, also uniformly broad and strap-shaped, arises immediately below the origin of the gluteus medius, from a small portion of the free edge of the sacrum, just below its juction with the ilium, also from the dense fascia covering the erector spince. It then passes over its fellow at its origin, and finally fuses with the broad flat tendon of the gastrocnemius just at the junction of its two heads.

Cuvier distinctly represents these two divisions of the muscles in his plates, and designates the last-described factor as the "Accessoire bicipital du demi-nerveux" ${ }^{3}$.

This latter portion of the muscle does not appear to have been present in the specimen described by Prof. Humphry. The editor of the second edition of Cuvier's 'Leçons' states in a footnote", concerning this muscle and the semimembranosus, that they, and sometimes only the latter, receive an accessory coccygeal portion. This arrangement, he says, is found principally in Rodents and in the Edentata.

Semimembranosus.--An enormously developed muscle, which arises from the whole extent of the tuberosity of the ischium, and from part of the ascending ramus of the bone, also, for some distance, from the side of the strong fascia covering the caudal muscles.

It passes upwards, its most posterior fibres of origin being fused for some distance with the biceps, to be inserted mainly into the deep layer of the aponeurosis common to it and the gracilis and sartorius; while a small portion, derived from the superior edge of the muscle, finds insertion into the edge of the femur, a little above the inner condyle, close to the origin of the inner head of the gastrocnemius.

${ }^{1}$ Op. cit. pl. 255, and 256. fig. 4.

'op. cit. pl. 255, and 256. figs. 1 and 3.
${ }^{2}$ Loc. cit. p. 311.

${ }^{4}$ Loc. cit. p. 522.

$4 \mathrm{~N} 2$ 
'Those fibres which are fused at origin with the biceps eventually join the inferior edge of the inner portion of the semitendinosus just before its insertion.

Biceps.-A large muscle, arising immediately below the gluteus maximus, seemingly from fascia covering the dorsal muscles, and fusing at the lowest part with the semimembranosus. Its upper portion speedily becomes differentiated from the rest of the muscle, and has a tendon developed along its inferior edge, which is finally inserted into a tubercle at the head of the fibula, near its junction with the tibia, being continuous, by its upper edge, with the aponeurosis or fascia in which the tensor vagina femoris is lost.

The rest of the muscle covers the whole of the triangular space included between a basal line drawn from its origin to its insertion and a popliteal apex formed by the semiflexed leg with the thigh, and terminates partly in fascia covering the front of the leg, and partly at the calcaneum, the muscular fibres being continued almost down to this bone.

Prof. Humphry ${ }^{1}$ notices only the latter mode of termination. Cuvier's representations of this muscle ${ }^{2}$ agree very well with my descriptions. The editor, moreover, of his 'Leçons' states ${ }^{3}$ that in the Orycteropus, as well as in the Armadillo, the biceps descends to the calcaneum.

In this animal, as in Dasypus, the biceps has no femoral head of origin. In the Ai and Anteater, on the contrary, according to $\mathrm{Meckel}^{4}$, this muscle derives part of its origin from the femur.

Gastrocnemius.-A muscle of great development. Its external head takes origin from the outer margin of the femur, immediately above the condyle, mainly by a strong tendon, in which a scsamoid bone, or "fabella" ", is developed, which plays over a smooth facet on the posterior part of the condyle. The inner head arises by a strong tendon from the inner edge of the shaft of the femur, immediately above the condyle of the same side, and fleshy from the internal lateral ligament. It joins with its fellow a little below the middle of the calf, to terminate eventually at the posterior extremity of the calcaneum, in a strong "tendo Achillis." A small slip is given off from the outer factor, to be inserted close to, and in advance of, the soleus.

The possession of a sesamoid bone in the origin of the gastrocnemius is by no means peculiar to the Orycteropus, as will be shown by the following instances.

Meckel describes, in his monograph on the two-toed Anteater ${ }^{6}$, a bone of this description as lying at the hinder aspect of the outer condyle of the femur, which, evidently, as in Orycteropus, belongs to the gastrocnemius, though not mentioned by him in connexion with this or any other muscle.

\footnotetext{
' Loc. cit. p. 312. $\quad{ }^{2}$ Op. cit. pl. 254. fig. 2, and 256. figs. 1 and 3.

${ }^{3}$ Loc. cit. p. 521.

5 "There is a fabella behind the outer condyle of the femur."-Prof. Owen ' On the Anatomy of Vertebrates,' vol. ii. p. 409 ; Ost. Catal. Coll. Surg. vol. ii. p. 422. Cuvier neither figures nor mentions this bone in his "Ossemens Fossiles.'

- Deutsche Archiv für die Physiologie, J. F. Meckel, fünfter Band (Halle und Berlin, 1819), p. 28.
} 
Douglas ${ }^{2}$ mentions the origins of the heads of the gastrocnemius in the dog "from the two ossa sesamoidea that adhere to the two condyles of the femur."

Krause, in his monograph on the Rabbit ${ }^{2}$, does not refer to any sesamoid in connexion with the gastrocnemius, but states that the plantaris arises from such a bone in the: neighbourhood of the "lateral condyle" of the femur.

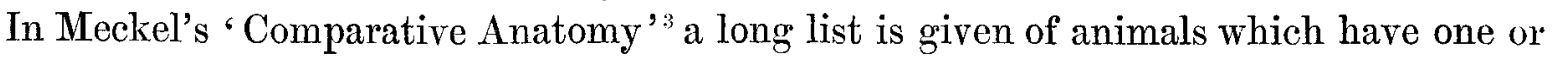
more of these bones in the gastrocnemius. On his authority, they occur in both tendons in many Apes, in the Mole, in the Agouti, Porcupine, and other Rodents. In Stenops, however, among Quadrumana, and, among Edentata, in the Aï and the Anteater, there is but one sesamoid; but in the latter Order they are larger than in other mammals. They are wanting in the Ornithorhynchus, among Monotremes, and in Man they are seldom present.

Dr. Ilg, in his monograph on sesamoid bones ${ }^{4}$, mentions the existence of bones of this character in the origins of the gastrocnemius in Cynocephalus sphinx (Simia sphinx, Linn.). Meckel ${ }^{5}$ has noted the same in his 'Comparative Anatomy' as occurring in this species of Ape.

Burdach $^{6}$, in a paper upon the myology of Inuus, Cynocephalus, and Cercopithecus (species not given), mentions the existence of such a bone at the outer as well as the inner condyle of the femur, in the origins of the gastrocnemius in these Apes.

Man is not exempt from the presence of such bones in the gastrocnemius; for, according to Sœmmering 7, "non raro tendo ventris externi os sesamoides excipit." The same anatomist remarks, after citing an author who had found two bones of this description, "forsan vero alterum fuit ossiculum, quod passim in bursis mucosis invenitur."

Henle, too, mentions the occasional occurrence of sesamoid bones in $\mathrm{Man}^{8}$, in the lateral and, more rarely, in the middle head (soleus) of the gastrocnemius, but regards them as pathological ossifications, such as are caused in other muscles by friction, $e . g$. in the median portion of the vastus in riders-a point which Fordham or Custance may some day have the privilege of illustrating.

In the fine skeleton of the Megatherium, preserved in the Museum of the Royal College of Surgeons, there is a sesamoid bone behind the outer condyle of the left femur. In all probability this was once imbedded in the gastrocnemius of this huge species of Sloth.

Soleus.-A flat and comparatively broad muscle, taking origin by a distinct tendon, imbedded in the origin of the deep flexor, from a sharp tubercle on the posterior aspect of the head of the fibula, and being inserted into the superior and inner face of the calcaneum.

Prof. Humphry makes no mention of this muscle by name. He may, however, with the old anatomists, have described it as an element of the gastrocnemius, in which case it will answer to his description of the third head of origin of this latter muscle ${ }^{9}$.

1 Myographiæ Comparatæ Specimen (London, 1707), p. 154.

${ }^{2}$ Die Anatomie des Kaninchens (Leipzig, 1868), p. $121 . \quad{ }^{3}$ Loc. cit. p. 634.

- Monographie der Sehnenrollen, zweiter Abschnitt, erste Abtheilung (Prag; 1824), p. 35.

${ }^{5}$ Loc. cit. p. $634 . \quad{ }^{6}$ Beitrag zur vergleichenden Anatomie des Affen (Königsberg, 1838), p. 47.

7 De Corp. Hum. Fabr. (Trajecti ad Mœnum, 1796), tome iii. p. 306.

${ }^{8}$ Muskellehre, p. 288.

s Loc. cit. p. 313. 
Meckel describes the soleus under the name of the "deep head" of the gastrocnemius, as being in the Edentata, at all events in the Aï and the Anteater, larger than the more superficial head of this muscle ${ }^{1}$. Further on he gives a special description of its arrangement in these animals, under the specific name of "Sohlenmuskel."

Plantaris.-This muscle, which Prof. Humphry has included in his description of the gastrocnemius, arises by a strong tendon slightly posterior to, and to the inner side of, the external head of the latter, and, after running down between the above muscle and the soleus, lies tendinous to the inner side of the tendo Achillis, just above the calcaneum, but, passing over this tendon at the posterior and inferior part of the bone, joins finally the plantar fascia. An offset, however, is distributed to each digit, which had the arrangement of the flexor sublimis in the upper extremity, the superficial layer forming a sheath for the deep or "perforating" flexor, the deeper layer being a "perforated" tendon, except in the case of the hallux.

The tendon of this muscle, though it does not terminate at the os calcis, has a strong attachment to a rough ridge which runs down along the inner side of this bone from the insertion of the soleus.

In the Aï, according to $\mathrm{Meckel}^{2}$, this muscle is well developed, and is fused with the "perforating" flexor.

Rapp describes the plantaris as absent in $M$. tamandua ${ }^{3}$.

Popliteus.-Is a well-developed muscle. It arises from a depression in the outer aspect of the external condyle by a strong flat tendon, covered by the origins of the peronei, and is inserted all along the posterior part of the tibia, from the head of this bone to its malleolus.

Flexor longus digitorum.-Arises from the posterior part of the fibula, completely covering in the most posterior of the peronei muscles, besides taking origin in part from the strong external lateral ligament, also from the interosseous membrane and inner edge of the tibia. At the heel it becomes tendinous; and the strong flat tendon, after running along the inner side of the calcaneal process, passes under a strong ligamentous bridge, stretched between the astragalus and plantar fascia, and, at about the middle of the sole, expands, soon to split into five "perforating" tendons, destined one for each digit, the hallux included.

Immediately before the tendon broadens out, as described above, there is given off from its fibular side, to join the peroneal tubercle of the calcaneum, a strong flat ligamentous or tendinous band. This is regarded by Prof. Humphry ${ }^{4}$ as the representative of the flexor accessorius, and is figured as such by Cuvier ${ }^{5}$.

As far as can be made out by the naked eye, there is no trace of muscular tissue in this rudimentary representative of the accessory flexor.

The "perforating" tendons terminate in their respective digits in the same manner as do those of the deep flexor in the fore foot, and complete their resemblance by presenting an indication of bifidity just before insertion.

The attempt at a differentiation of a flexor longus hallucis from the substance of the

\footnotetext{
1 Vergleich. Anat. p. 630 et seq. 2 Loc. cit. p. $656 . \quad 3$ Op. cit. p. 50.

1 Loc. cit. p. 317.
} 
common flexor of the toes will be noticed under my description of the tibialis posticus.

Rapp describes, under the old name of "caro quadrata Sylvii," an accessory flexor as present in Myrmecophaga tamandua ${ }^{1}$. According to the same authority, the hallux in this animal has no special flexor, but shares with the other digits the tendinous supply of the common flexor.

Flexor brevis digitorum.-This muscle, as in the case of Dasypus, was absent.

Meckel observes ${ }^{2}$ that it appears most correct to admit that the Edentata are deprived of a small flexor communis, and that that which is described as such represents the short head of the perforating flexor, for the reason that the tendons of the former are not perforated, and that the analogy with the anterior member militates in favour of this conclusion.

Tibialis posticus.-This muscle took origin from the inner aspect of the head of the fibula, and from the opposite-looking edge of the posterior portion of the tibia, and in part from the interosseous membrane, the anterior tibial vessels passing between its fibular and tibial heads of origin. It is intimately connected, for nearly the whole of its length in the calf, with the flexor digitorum. A little above the inner malleolus it is continued into two flat tendons, which pass under a strong ligamentous pulley or arch, situated on the posterior aspect of the above process.

The deeper of the two tendons, after passing under a strong internal lateral ligament of the ankle, which separates it from its fellow, terminates at the posterior part of the inferior ridge of the ento-cuneiform bone (" hinder part of scaphoid," according to Prof. Humphry ${ }^{3}$ ); while the more superficial, belonging to the fibular belly of the muscle, divides into two branches, one of which joins by a broad expansion the tendon of the common flexor, while the other terminates at the posterior part of the sesamoid ossicle ${ }^{4}$ which lies alongside of the ento-cuneiform bone, and which is attached, by a ligament proceeding from its anterior extremity, to the inner side of the base of the proximal phalanx of the hallux.

Cuvier's representation of the termination of the last-named tendon is very clear ${ }^{5}$.

The broad expansion of the first-mentioned branch of the superficial tendon had connexions which are of interest, since they tend to show a differentiation, in an animal belonging to the Bruta, of a flexor longus hallucis from the common flexor muscle; for, posteriorly, it was continued tendinous into a muscular offiset from a portion of the common flexor which arose from the lower part of the fibula, while, anteriorly, it took a large, nay, almost a principal share in forming the flexor tendon of the hallux.

An arrangement somewhat similar to that just described is occasionally met with in Man, according to Bichat ${ }^{6}$, in the tendon of the tibialis posticus, of which, besides its usual prolongation to the ento-cuneiform bone, "souvent autre prolongement, qui est externe, se poste sous la plante du pied, et se confond avec ses ligamens."

' Op. cit. p. $50 . \quad{ }^{2}$ Op. cit. p. $657 . \quad{ }^{3}$ Op. cit. p. 315.

1 No mention whatever is made of this ossicle (which exists in Dasypus proportionally better developed) by Prof. Humphry. According to Cuvier, 'Ossemens Fossiles,' loc. cit. p. 136, "l'os surnuméraire du bord interne [of the entocuneiform], s'il existe, est fort petit."

${ }^{5}$ Anat. Comp. pl. 256. fig. 6.

- Traité d'Anatomie Descriptive (Paris, 1802), tome ii. p. 324. 
The muscles which arise from the extensor surface of the leg in Orycteropus are well marked off into three distinct groups, each of which passes under a strong ligamentous pulley peculiar to it.

The tibial group comprises muscles proper to the hallux; such are the extensor proprius of this digit, and the tibialis anticus.

The middle group includes but the four tendinous offsets of the extensor communis, while under the group on the fibular side are comprised the peroneal muscles.

Peronei.-These muscles are so blended together at origin that it is not easy to isolate them for description. They arise along the outer edge of the fibula, in close opmpany with the extensor communis, from the inward-looking aspect of the head of the bone, and from the external lateral ligament and outer semilunar cartilage.

Just above the outer malleolus, they become tendinous; and their tendons, four in number, are kept in place behind this strongly projecting process by a ligamentous band or pulley.

The most anterior at origin passed over the extensor brevis digitorum to join the expansion of the common extensor, at the base of the proximal phalanx of the fourth digit, sending off also a slight slip to terminate in like manner at the little toe.

A second passed to the outer side of the base of the proximal phalanx of the fifth digit, joining here the metatarso-phalangeal expansion of the common extensor tendon.

Another terminated at a very strong tubercle developed on the outer side of the base of the metatarsal bone of the same digit.

The two last-described muscles seem to answer tolerably fairly to the peronei tertius and brevis of human anatomy, respectively.

The first muscle seems to answer very fairly to one described by Mr. Mivart and Dr. Murie, in their paper on the "Anatomy of the Crested Agouti" ", as the peroneus quarti digiti; or it may be regarded as the muscular resultant developed by the fusion of this with the peroneus quinti digiti.

The tendon of the homologue of the peroneus longus passed over a groove in a tubercle situated on the outer side of the head of the os calcis, and, on gaining the sole, took a turn at a right angle, and passed under the strong plantar ligaments to its usual insertion at the fibular side of the base of the metatarsal of the hallux. Soon after its entrance into the sole, it detached, as described by Prof. Humphry ${ }^{2}$, an offset from its anterior edge, which was inserted into the tibial side of the metacarpal of the fifth digit. Record of a similar arrangement will be found in my paper on the myology of Dasypus. No reference to this important point has been given, as far as I am aware, either by Meckel or by Cuvier.

Such a disposition of the tendon of the peroneus longus as that just described obviously ensures the simultaneous adduction, towards the middle line of the foot, of the hallux and fifth digit.

Tibialis anticus.-A strong, well-developed muscle, arising from the arch formed by the junction of the tibia and fibula at their upper part-also by a small slip from the anterior ridge of the former bone, just below the insertion of the patellar ligament-in

\footnotetext{
1 Proc. Zool. Soc. June 1866.

: Loc. cit. p. 319.
} 
part, too, from the outer edge and a small part of the anterior face of this ligament, and from the tendon of the biceps. At the inferior extremity of the tibia the muscle suddenly contracts, and passes tendinous under a very strong ligamentous pulley which is shared by the extensor hallucis. Two tendons are developed from this muscle, one of which passes to the inner side of the base of the metatarsal of the hallux; while the other, after coursing down the side of the foot behind the former tendon, is inserted into the anterior part of the inferior edge of the ento-cuneiform bone, and has also a slight communication with the base of the metatarsal.

This muscle, as I have described, possesses but one terminal tendon in Dasypus.

In the Ä̈ and Anteater, according to Meckel ${ }^{1}$, the tibialis anticus has two heads of origin, which, however, meet in a common tendon which is inserted into the rudiment of the hallux. Meckel hints that the external of these two factors may represent the extensor of the hallux.

Dr. Ilg ${ }^{2}$ describes in Cynocephalus sphinx a differentiated slip from this muscle, which he terms "abductor hallucis longus," and states to be absent in man. It was fused at origin with the tibialis anticus, and was inserted into the plantar aspect posteriorly of the metatarsal of the hallux.

This muscle, according to Burdach ${ }^{3}$, has two terminal tendons in Cercopithecus; but in Inuus and Cynocephalus one of these belongs to a differentiated muscular slip. He holds that in each case the supernumerary muscle or tendon must be regarded as an abductor longus hallucis.

The description of the tibialis anticus in Nycticebus tardigradus is thus concluded by Mr. Mivart and Dr. Murie :- "There is no trace whatever of any division of the tendon of this muscle, à fortiori not of its muscular part" ".

Church describes, in the Orang, a splitting into two parts of the tendon of this muscle, as well as of that of its serial homologue in the hand, the extensor ossis metacarpi pollicis ${ }^{5}$.

Prof. Iuxley, in his lectures on the Mammalia at the Royal College of Surgeons, remarked that the division of the tendon of the tibialis anticus was, in the Chimpanzee, carried up into its muscular fibres, in some cases quite to their origin, so that the anterior portion had been described by Cuvier and others as a distinct muscle-the abductor hallucis longus. The tendon of the extensor ossis metacarpi pollicis is also in this Ape, according to Prof. Huxley, double. In the same course of lectures, the terminal tendons of both of these serially homologous muscles were described as double in the Gorilla, in the Orang, and in Hylobates. This differentiation of the tendon did not, however, extend to the muscle itself ${ }^{6}$.

Scemmering describes, in his work upon Human Anatomy ${ }^{7}$, a division of the tendon of the tibialis anticus before insertion, the larger portion terminating at the cuneiform bone, the smaller at the metatarsal of the hallux.

According to Henle, the tendon of the tibialis anticus in Man divides before its inser-

${ }^{1}$ Op. cit. p. $624 . \quad$ 2 Op. cit.p. $39 . \quad{ }^{3}$ Op. cit. p. 45.

4 Proc. Zool. Soc. February $1865 . \quad{ }^{5}$ Nat. Hist. Rev. Jan. 1862, pp. 83 and 88.

- Medical Times and Gazette, 1864, April 23rd, May 14th and 28th, June 11th. $\quad{ }^{7}$ Loc. cit. p. 319. VOL. XXVI. 
tion. The insertion-tendon of the abductor pollicis longus is also, be observes, "not seldom double" ${ }^{1}$.

Theile makes no mention of the division of the former muscle in Man.

Extensor proprius hallucis.-Arises by a flat delicate tendon from about the middle third of the anterior edge or ridge of the fibula. It then runs obliquely outwards, till it passes under the strong pulley common to it and the tibialis anticus, when its direction is changed to one straight for its proper digit. At the astragalo-scaphoid articulation it becomes tendinous; and the straight continuation of the tendon, after expanding over the proximal phalanx of the hallux, terminates at the distal joint of this digit.

The tendon, moreover, a little posterior to the metatarso-phalangeal articulation, gives from its fibular side an offset to join one sent off to meet it from the inner of the common extensor tendons, which, after this junction, is continued to the base of the proximal phalanx of the second toe, there to join the expansion of the tendon of the extensor communis sent to this digit. This arrangement much resembles that which $I$ have described and figured as existing in Dasypus, only that there is no pulley attached to the accessory ossicle which might serve to change the direction of the tendon of the extensor hallucis.

Rapp $^{2}$ describes the tendon of this muscle in $M$. tamandua as splitting into two branches, which pass to the first and second digits respectively, the latter of these branches entering also into communication with the tendon of the common extensor.

Extensor communis digitorum.-Arose by a strong flat tendon from the outer aspect of the external condyle of the femur, being covered by the lateral patellar ligament at this joint. It had scarcely, if any, origin from the tibia and fibula. Its muscular belly had about one-third of the bulk of that of the largely developed tibialis anticus. Just before it gains the dorsum of the foot, the muscle passes under a very strong ligamentous loop or pulley, which is attached to the anterior portion of the calcaneum, and, slightly, to the astragalus. Here it contracts, and divides into four equal-sized tendons.

The arrangement of these tendons, though at first sight somewhat complicated, may, I think, be best simplified thus :-The two innermost were fused together, so as to form a kind of aponeurotic expansion or web on the dorsum of the foot. This compound factor may be conveniently termed the "tibial" division. The "fibular" division was formed by a similar fusion of the two outermost tendons; and both "tibial" and "fibular" divisions had, moreover, a slight communication with each other.

The tendons, though thus fused together, may, however, each be traced with a considerable degree of certainty to its proper destination.

The first tendon, beginning from the tibial side, sent a branch to join that of the extensor hallucis; but the main portion was continued straight to the terminal phalanx of the second digit, expanding, however, over the metatarso-phalangeal articulation of this digit.

The second tendon passed to the tibial side of the tendinous expansion over the metatarso-phalangeal joint of the middle digit, and was also continued to the terminal phalanx. The expansion was joined on its fibular side by the inner of the two branches

\footnotetext{
${ }^{1}$ Muskellehre, pp. 211 and 276.

${ }^{2}$ Op. cit. p. 50.
} 
into which the third tendon divides. The fibular branch of the third tendon, after joining the expansion over the metatarso-phalangeal joint of the fourth digit, was continued also to the terminal phalanx of this digit.

The fourth tendon passed to the terminal phalanx of the fifth digit, after joining the expansion over the metatarso-phalangeal articulation. This tendon may, possibly, take some share in forming what I have termed the fibular branch of the third tendon, but which Prof. Humphry describes as the tibial branch of the fourth ${ }^{1}$.

Each of the tendons of the extensor communis had, at its metatarso-phalangeal expansion, a patella-like sesamoid bone developed in it, which bones appear to belong strictly to the deep layers which find attachment at the base of the middle phalanges of their respective digits.

These bones do not appear to have been present in the specimen examined by Prof. Humphry. Many of them are preserved in the skeleton of Orcyteropus in the Museum of the Royal College of Surgeons. A similar sesamoid, developed in a similar position, is present in the terminal tendon of the extensor hallucis.

Extensor brevis digitorum.-This muscle arose from the outer aspect of the calcaneum, superior to the origin of the abductor minimi digiti-also from the anterior portion of the bone, especially the tubercle which articulates laterally with the astragalus. It then passed obliquely forwards to be inserted into the inferior aspect of what I have termed the "fibular" division of the tendons of the extensor communis. It also joined, by means of two strong tendons, the tibial side of the second tendon and the fibular side of the first tendon respectively, of the above division, just before these expand over the metatarso-phalangeal joints of their proper digits-an arrangement which evidently favours the approximation of the second and middle digits, which are not bound together so closely as their homologues are in Dasypus by skin and subjacent tissue.

Another portion of the muscle is inserted fleshy into the first tendon at the point where it gives off the lateral branch to the tendon of the extensor hallucis. The extensor brevis does not appear to enter into any direct communication with the fourth tendon of the common extensor.

Prof. Humphry ${ }^{2}$ describes this muscle as possessing three tendons; but the only distinct offsets deserving the term, in the animal which I examined, were those described as passing to the extensors of the second and middle digits.

Abductor minimi digiti.-Fairly developed. It is a flat muscular band, which takes origin from the smooth outer face of the calcaneal process, just below the origin of the preceding muscle, and has a broad fleshy insertion into the tubercle at the outer side of the base of the metacarpal bone of the fifth digit, and is also continued as a tendon to a sesamoid bone lying at the base of the proximal phalanx of the same digit.

Flexor brevis digiti quinti $\left(\right.$ Henle $\left.^{3}\right)$.- This muscle arose slightly from the calcaneum, but principally from that portion of the plantar ligament which was inserted into the base of the metatarsal of the fourth digit. It gradually widened towards its termination, and had a fleshy insertion into the base of the proximal phalanx of the fifth digit.

Prof. Humphry makes no mention of this muscle as existing in his specimen.

Opponens digiti quinti (Henle).-This muscle, described by Prof. Humphry ${ }^{4}$ under the
Loc. cit. p. 317.
Loc. cit. p. 318.
3 Muskellehre, p. 301.
${ }^{4}$ Loc. cit. p. 317.
402 
name of adductor minimi digiti, took origin from the plantar ligament, at about the point of contact of the bases of the metatarsals of the third and fourth digits. After passing obliquely across to the tibial side of the fifth digit, it joined the lower layer of the extensor tendon on the dorsum of the proximal phalanx of this digit.

Plantar muscles of hallux.-A thin fusiform slip, taking origin from the anterior extremity of the ento-cuneiform bone, on its plantar aspect, and being inserted into the sesamoid at the fibular side of the base of the proximal phalanx of the hallux, in company with the terminal portion of the muscle termed by Prof. Humphry adductor hallucis.

This latter muscle, which may represent the outer (fibular) head of the flexor brevis, took origin from the strong plantar ligament, at the level of the base of the metatarsal of the second digit (the " middle metatarsal," according to Prof. Humphry).

The first-described muscle bears a great resemblance, both in origin and insertion, to one which I found last year in the right foot of a seaman at the "Dreadnought" Hospital Ship, and which is considered by Mr. Wood to be the plantar representative of the "interosseus palmaris volaris" of the hand ${ }^{1}$.

Since, however, this muscle does not coexist with a complete set of the normal muscles of the hallux, a certain conclusion can scarcely be arrived at that it is the homologue of the above-described human "abnormality," seeing that either the adductor hallucis or the fibular head of the flexor brevis of this digit may lay just claim to it as a displaced representative.

As in the specimen described by Prof. Humphry, no proper abductor hallucis appeared to be present.

Lumbricales.-These muscles are four in number. They have origins similar to those of their hornologues in Dasypus, arising in the interspaces of the tendons of the flexor longus, where these branch off from the common tendinous expansion of the muscle. They differ, however, in continuing single to their insertion, which is into the middle of the tibial side of the proximal phalanges of the second, third, fourth, and fifth digits. The hallux, it will be seen, unlike its homologue in Dasypus, has no lumbricalis.

These muscles resemble their homotypes in the upper limb in not being connected with the sheaths of the extensor tendons.

Cuvier gives a very good representation of them in one of his plates ${ }^{2}$.

The Ai, according to $\mathrm{Meckel}^{3}$, has no lumbricales, although the flexor longus is well developed.

Rapp mentions these muscles as present in M. tamandua ${ }^{4}$, but makes no statement relative to their number or mode of termination.

The Interossei proper are confined to the three middle digits. They are six in number, and are so divided that each digit has one on either side.

\footnotetext{
${ }^{1}$ Proc. Royal Soc. May 1867, p. 543. I have Mr. John Wood's kind permission to correct here an error in his description of the muscle which forms the subject of this foot-note. My own description, which accompanied a copy of my original sketch, which I gave to Mr. Wood, was as follows:-- Muscular slip arising from the fascia in the neighbourhood of the articulation between the internal cuneiform bone and the metatarsal bone of the hallux, and of the insertion of the tibialis anticus, and becoming fused with the tendon of the outer head of the flexor brevis of the hallux. April 17, 1867."

2 Op. cit. pl. 256. fig. 6 .

sp. cit. p. 661 .

Op. cit. p. 50 .
} 
They each arise from a side of the strong ligament, which passes, forked at both extremities, into a resemblance to an $X$, from the plantar aspect of the base of the metatarsal to the sesamoids at the base of the proximal phalanx of each digit, and are inserted into the sides of the lateral expansion of the extensor tendon at the metacarpo-phalangeal articulation, besides having attachment to the sesamoids at either side of the bases of the proximal phalanges of their respective digits.

Their action appears to be, especially when all united, principally one of flexion; separately, they might seem to abduct from, or adduct towards the middle line of the sole the digits to which they are respectively attached.

They who may have occasion to refer to this and to the preceding paper for facts (it is sincerely hoped that the descriptions of the muscular phenomena there noted are worthy of the name) may, perchance, expect to find at this stage a concluding colligation of these under a generalization of some sort. This, I fear, I am not prepared to offer ; for neither can it be affirmed, on the one hand, that the muscular varieties which have been the subject of these pages lave any precise morphological significance, nor, on the other hand, can they be regarded solely from a teleological point of view.

For, with regard to morphology, if muscular peculiarities are not to be regarded, as some hold, as "subsidiary to osseous arrangements," the converse can scarcely be maintained-namely, that osseous structures are not modifiable, at any rate as regards their offshoots (or "processes" as anatomists term them), by the condition of the development of the muscles which find attachment to these; for if this be not already granted, or, at all events, tacitly assumed, how comes it that (to take one out of many instances) in the exhumation of human remains for purposes antiquarian, ethnological, or medico-legal ${ }^{1}$, the development of the processes of certain bones is taken greatly into account as an indication of the muscular condition, or even of the sex (in the absence of pelvic evidence), of the individual of whom these once were members?

Now these very bony processes, which are allowed to be affected by the muscles to which they afford attachment ${ }^{2}$, are, in recent animals, in conjunction with the leading characters of other physiological systems, such as the digestive, generative, or nervous, chosen as a basis of classification. Take, for instance, the third trochanter on the femur of an Ungulate (possibly the niggard dole extorted by importunate muscular wants), which enables us to predicate of its once possessor that it was odd-toed, that its horn or horns (if any were present) were median, and not lateral, that its stomach was simple, while its cæcum was large and sacculated, and that the placenta which brought to it nourishment in foetal life was of the "diffused," "non-deciduate" variety.

On the evidence, moreover, of such "processes," to a great extent, animals long since extinct are distributed among the classes which are provisionally formed for them and their modern representatives. By the aid of these, in great measure, have the Mylodon

1 "The bones of the female are lighter, more cellular, less marked by asperities, and less curved by muscular action than those of the male; the processes are less strongly marked."-Guy's 'Principles of Forensic Medicine,' 2nd ed. p. 20.

' See Herbert Spencer's 'Principles of Biology,' vol. ii. p. 335 et seq. (Lond. 1867); 'Trousseau, ‘Clinique Médicale,' tome iii. chap. 84, "Rachitis" (2ième édit., Paris, 1865). 
and Megatherium found a place among the Sloths, and the Glyptodon supported a claim of kinship to the Armadillo'.

If, on the other hand, the variations of muscles can reasonably be regarded as influenced by, or "as subsidiary to," the character of their bony attachments, before it can be determined what morphological value the former possess, we must first ascertain the probable amount of osseous influence which has been brought into play (a task towards the performance of which neither physiology nor pathology appears as yet to promise much aid), or, at all events, obtain a sure knowledge of the homologies of the subjacent bony framework (an inquiry in which, as regards the upper limb, the researches of Rathke and Parker will stand us in good stead, but in the case of the lower member there may yet be some groping about and stumbling); or, in default of such aids, the consideration of the skeleton must be set aside, and, regarding muscles per se, we must construct for our use "a typical vertebrate myozoon," to which, Procrustes-like, we can, as accurately as may be, adapt our muscular waifs and strays.

As regards teleology, it does not appear sufficient to consider the end of the general arrangement of the muscles of any given limb, to the exclusion of the special items contributed towards this end, or physiological total, by distinct muscles; for, to take an instance, if we content ourselves with the general observation that it is burrowing with which the muscular arrangement in the fore limb of the Armadillo, Aard-vark, and Mole appears to be chiefly concerned, we run the risk of overlooking the divers means by which this seemingly uniform result is brought about, and may omit to accredit an important share in the work, in the case of the two former animals, to the hugely developed and combined triceps and dorso-épitrochlien, and, in the case of the latter, to the teres major, a muscle which, as both Meckel and Cuvier have remarked, reaches an enormous degree of development in this animal'

Whether the likenesses or unlikenesses which certain muscular systems in Dasypus and Orycteropus may bear towards each other be due to a congruity, or the reverse, in their relations (be they morphological or teleological), or be brought about by a similarity or dissimilarity in conditions of existence (a plastic influence to which, according to

1 The soundness of such claim, however, in the eyes of certain good authorities is by no means as yet distinetly proven. M. Pouchet, for instance, in a résumé of a paper upon the osteology of Glyptodon clavipes, G. giganteus, and Hoplophorus euphractus, remarks, "Ceei tient, comme nous l'avons dit, à ce que nous manquons des points de comparaison nécessaires, puisque nous ne connaissons complétement à peu près aucun de ces animaux. Ce n'est pas avee le cou des uns, le bassin des autres, la carapace de ceux-ci et la queue de ceux-là qu'on peut faire des distinctions ou des rapprochements définitifs, les animaux semblables par un de ces points pouvant différer énormément pour tous les autres."-Contribution à l'Anatomie des Édentés, par Georges Pouchet, Ch. Robín, Journ. de l'Anat. et de la Physiol. vol. iii. p. 351, 1866.

${ }^{2}$ Meckel says of this muscle (op. cit. p. 500), "Ungeheuer stark, wohl am stärksten ist er bein Maulwurf, wo er den ganzen Untergrätenmuskel bedeckt."

The same muscle is clearly represented by Cuvier in one of his figures of the myology of the Mole (Anat. Comp. pl. 80); and in the short notes appended to the plate, it is stated that "Le grand rond est extrêmement puissant et tellement saillant que dans la fig. 1 on pourrait croire qu'il se fixe au cubitus."

In the Mole-Rat of the Cape (Mus Capensis, Linn.), the teres major does not attain so great a development (see pl. 216, op. cit.); for " au lieu de fouir avec la rapidité merveilleuse que montrent ces insectivores (Tanpes) pour atteindre les larves d'insectes ou les vers, les Rats-Taupes, qui vivent de racines, cheminent plus lentement dans leurs galeries." 
some, due weight has not yet been given in biological speculations ${ }^{1}$ ), is a question of which, from the quantity and the quality of the facts at my disposal, I confess myself unable to offer a satisfactory solution; and, as a slight excuse for my reluctance to generalize, I bring forward, in conclusion, the following words of a great thinker" : " General observations drawn from particulars are the jewels of knowledge, comprehending great store in a little room; but they are therefore to be made with the greater care and caution, lest, if we take counterfeit for true, our loss and shame be the greater when our stock comes to a severe scrutiny."

\section{BIBLIOGRAPHY ${ }^{3}$.}

Azara. Essais sur l'Histoire Naturelle de Quadrupèdes de la Province du Paraguay, par Don Felix D'Azara (traduits sur le Manuscrit inédit de l'Auteur, par Moreau Saint-Méry), vol. ii. Paris, 1801.

BdRdach. Beitrag zur vergleichenden Anatomie des Affen. Königsberg, 1838.

Churcr. On the Myology of the Orang Utang (Natural History Review, October 1861 and January 1862).

Covrer. Anatomie Comparée, recueil de planches de myologie dessinées par Georges Cuvier ou exécutées sous les yeux, par M. Laurillard. Folio. Paris, 1855.-Leçons d'Anatomie Comparée (Seconde édition), tome i. Paris, 1835.-Ossemens Fossiles (Nouvelle édition), tome v. Paris, 1823.-Règne Animal (Mammifères).

Cyclopædia of Anatomy and Physiology, vol. ii.

Cyclopædia of Natural History, vol. i. London, 1856.

Darrfur's Sketches, representing the Native Tribes, Animals, and Scenery of Southern Africa. London, 1820.

Douglas. Myographiæ Comparatæ Specimen. London, 1707.

Ecker. Die Anatomie des Frosches. Iste Abtheilung. Braunschweig, 1864.

Gratrolet. Recherches sur l'Anatomie de l'Hippopotame, publiées par les soins du Dr. Edmond Alix. Paris, 1867.

Gray. Revision of the Genera and Species of Entomophagous Edentata, by Dr. John E. Gray, F.R.S. (Proceedings of the Zoological Society, 1865).

Grober. Ueber den Musculus Epitrochleo-Anconeus der Menschen und der Säugethiere, mit 3 Tafeln (Mém. de l'Acad. Imp. des Sciences de St. Pétersbourg, $7^{\text {me }}$ sér. tome x. no. 5).

HaLLET. An account of the Anomalies of the Muscular System met with in the Dissecting-room of the University, during the years 1846-47; with general remarks (Edin. Med. and Surg. Journ. vol. 1xix.), Jan. 1848.

HFine. Muskellehre. Braunsehweig, 1858.

Homphry. On the Myology of Orycteropus capensis and Phoca communis, by Professor Humphry (Journ. of Anat. and Phys. 2nd ser. vol. i.). Cambridge, 1868.

HuxLer. Hunterian Lectures on the Mammalia, Royal College of Surgeons (Medical Times and Gazette, and Reader, 1864).

ILG. Monographie der Sehnenrollen. Prag, 1824.

Kradse. Die Anatomie des Kaninchens. Leipzig, 1868.

1 “Mr. Darwin's Hypotheses, by George Henry Lewes," Parts I. and III. Fortnightly Reriew, April (p. 372) and July (p. 78) 1868.

With regard to habits, these two animals agree in their mode of procuring food; and therefore a certain general, and even special, similarity in the structure of their limbs may reasonably be expected; but, on the other hand, the restricted ant-diet of the sluggish Aard-vark must cause this animal to differ in some points from the omnivorous, and even "ghoul"-like (see Azara, 'Essais,' vol. ii. p. 127, and Rengger, 'Säugethiere von Paraguay,' p. 281), active Armadillo. For some very suggestive remarks upon the respective values of kind of food and the manner in which such food is procured, as foundations for classification, see Andrew Murray's 'Geographical Distribution of Mammals,' p. 219.

' Locke, 'On the Conduct of the Understanding.'

${ }^{3}$ It were unjust of me not to acknowledge here the great obligations under which I am to Prof. Rolleston for placing in my hands for reference a large proportion of the works included in the following list. 
Macalister. On the Homologies of the Flexor Muscles of the Vertebrate Limb (Journ. of Anat. and Phys. 2nd ser. vol. i.). Cambridge, 1868.-Contributions toward the formation of a correct System of Muscular Homologies (Ann. and Mag. of Nat. Hist. 4th ser. vol. i.). 1868.

Myckel. Anatomie des zweizehigen Ameisenfresser (Archiv für dic Physiologie, fünfter Band). Halle und Berlin, 1819.--System der vergleichenden Anatomie, dritter Theil. Halle, 1828.-Ornithorhynchi paradoxi Descriptio Anatomica. Lipsiæ, 1826.

Mivart. On some points in the Anatomy of Echidna hystrix (Trans. Linn. Soc. vol. xxv.). 1866.

Mrvart and Murie. Observations on the Anatomy of Nycticebus tardigralus (Proc. of Zool. Soc. Feb. 1865).-On the Myology of Hyrax capensis (Proc. Zool. Soc. Apr. 1865).-On the Anatomy of the Crested Agouti (Proc. Zool. Soc. June 1866).

Murray. Geographical Distribution of Mammals. London, 1866.

Osteological Catalogue of the Hunterian Museum, Royal College of Surgeons, rol. ii.

Owex. On the Anatomy of the Great Anteater ('Trans. Zool. Soc. 1854).--On the Anatomy of Vertebrates, vol. ii.

PARkEr. A Monograph on the Structure and Development of the Shoulder-Girdle and Sternum in the Vertebrata. Ray Society, 1868.

PFeifrer. Zur vergleichenden Anatomie des Schultergerüstes und der Schultermuskeln. Giessen, 1854.

Podchet. Mémoire sur le Grand Fourmilier, par Georges Pouchet. 1 $1^{\mathrm{e}}$ Livraison. Paris, 1867.-Contribution à l'Anatomie des Ëdentés (Ch. Robin, Journ. de l'Anat. et de la Physiol. vol. iii. 1866).

Kapp. Anatomische Untersuchungen über die Edentaten. Tübingen, 1852.

lifngGer. Naturgeschichte der Säugethiere von Paraguay. Basel, 1830.

Rolleston. On the Homologies of certain Muscles connected with the Shoulder-Joint (Trans. Linn. Soc. vol. xxvi. 1868).

Scemmerivg. De Corporis Humani Fabricâ, vol. iii. Trajecti ad Mœnum, 1796.

Turner. On the Musculus Sternalis (Journ. of Anat. and Phys. 1st ser. vol. i.). Cambridge, 1867.

Woop. On Human Muscular Variations and their relation to Comparative Anatomy, by John Wood, F.R.C.S. (Journ. of Anat. and Phys. 1st ser. vol. i.) Cambridge, 1867.-Variations in Human Myology (Proceedings of the Royal Society, June 1865, June 1866, and May 1867).

\section{EXPLANATION OF THE PLATES.}

\section{Plate XLV.-Principal Muscles of the Upper Extremity.}

Fig. 1. Inner aspect of Arm and Forearm, together with contiguous portions of Trunk, and Radial half of Extensor surface of Forefoot. Left side.

P C. Panniculus carnosus.

M S. Musculus sternalis.

A B. Acromio-basilar.

D H. Dermo-humérien.

S M. Sterno-mastoid:

C M. Cleido-mastoid.

S. Scalenus.

O E. Obliquus externus.

S C. Subclavius.

D. Deltoid.

PM. Pectoralis major.

PMN. , minor.

L D. Latissimus dorsi. 
C B. Coraco-brachialis.

B. Biceps.

D E. Dorso-épitrochlien.

T. Triceps.

E A. Epitrochleo-anconeus.

S L. Supinator longus.

S B. , brevis.

E C R. Extensor carpi radialis.

EOMP. „, ossis metacarpi pollicis.

ECD. , " communis digitorum.

$\mathrm{P}$ T. Pronator radii teres.

F C R. Flexor carpi radialis.

FSD. " sublimis digitorum.

FCU. , carpi ulnaris.

FPD , profundus digitorum.

A BI. Abductor indicis.

L. Lumbricalis.

* Submaxillary Gland.

Fig. 2. Middle layer of Muscles at Upper part of Thorax, left side.

R A. Rectus abdominis.

E O. Obliquus externus.

E I. External intercostals.

S. Scalenus.

P MN. Pectoralis minor.

PM. , major.

S C. Subclavius.

S M. Sterno-mastoid.

Fig. 3. Deep palmar muscles, including Interossei, right side.

P T. Pronator radii teres.

P L. Palmaris longus.

F C R. Flexor carpi radialis.

F S D. " sublimis digitorum.

FPD. " profundus digitorum.

FCU. , carpi ulnaris.

$P Q$. Pronator quadratus.

A M D. Abductor minimi digiti.

L. Lumbricalis.

* Annular ligament. (The flattened oval sesamoid is seen in the ulnar half of the divided ligament.)

\section{Plate XLVI.-Principal Muscles of Lower Extremity.}

Fig. 1. Inner aspect of thigh, and extensor surface of leg and foot. Left side.
I P. Ilio-psoas.
G R. Gracilis.
S. Sartorius.
S M. Semimembranosus.
S T. Semitendinosus. 
P. Pectineus.

O E. Obturator externus.

A B. Adductor brevis.

A L. " longus.

A M N. , minimus.

R. Rectus.

VI. Vastus internus.

G. Gastrocnemius.

T A. Tibialis anticus.

E C D. Extensor communis digitorum.

E P H. , , proprius hallucis.

E B D. " brevis digitorum.

P L. Peroneus longus.

PB. " , brevis.

PT. , tertius.

PQ. $\quad$ quinti digiti.

Fig. 2. Muscles connected with the Great Trochanter. Right side.

G M X. Glutæus maximus.

GM D. , medius.

G M N. , minimus.

PY. Pyriformis.

O I. Obturator internus.

G S. Gemellus superior.

G I. Gemellus inferior.

A M N. Adductor minimus.

S T. Semitendinosus.

$\mathrm{S} \mathrm{T}_{2}$. Semitendinosus, sccond portion.

Fig. 3. Deep plantar muscles, including Interossei. Left side.

S O. Soleus.

P L N. Plantaris.

T A. Tibialis anticus.

T P. Tibialis posticus.

P L. Peroneus longus.

P B. , brevis.

PT. , tertius.

F L D. Flexor longus digitorum.

F A. Flexor accessorius (rudimentary)

E B D. Extensor brevis digitorum.

L. Lumbricalis.

A B M D. Abductor digiti minimi.

F B D Q. Flexor brevis digiti quinti.

OD Q. Opponens digiti quinti.

A H. Adductor hallucis.

F 1 H. Flexor brevis hallucis.

* Accessory ossicle of Entocunciform bone. 

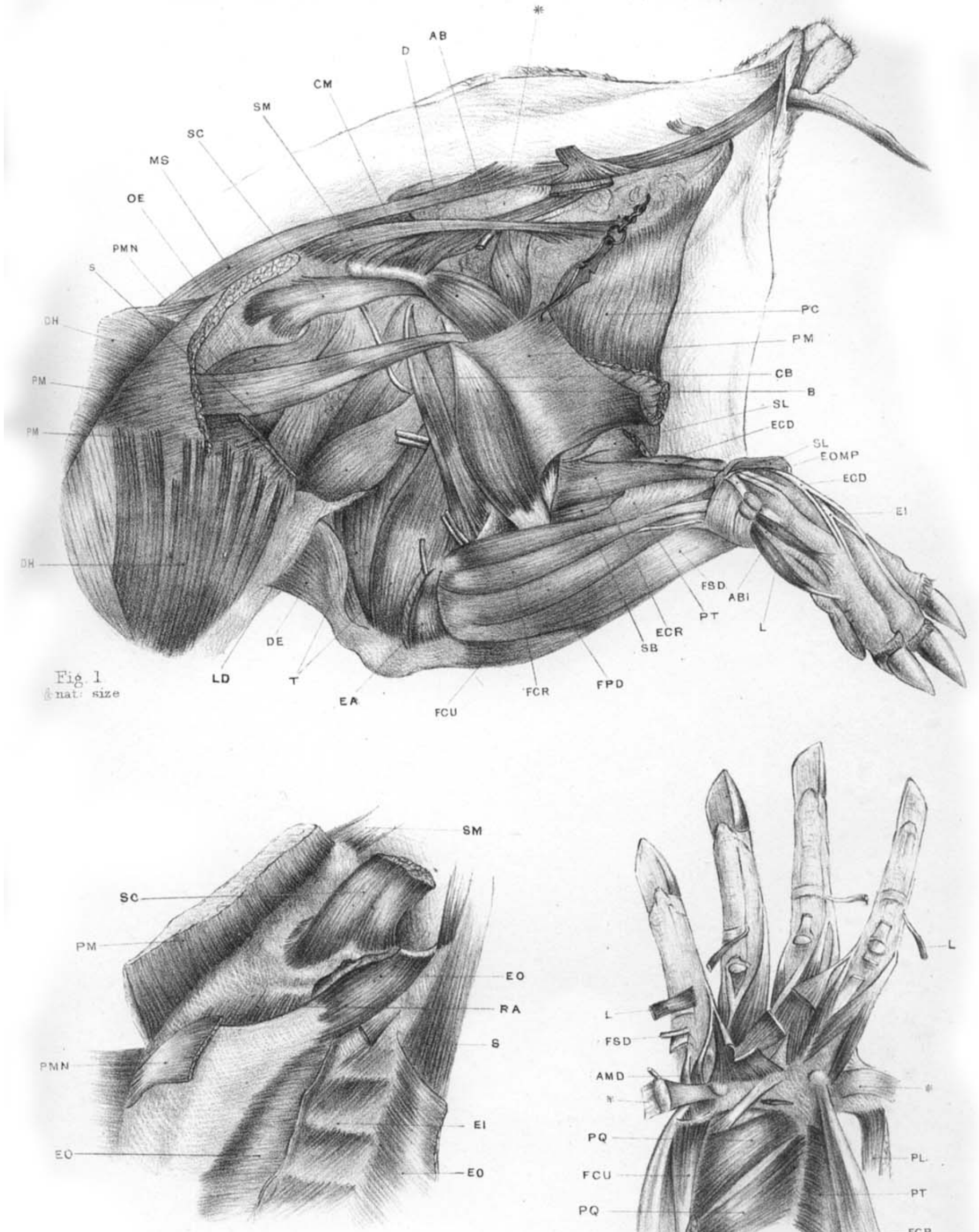

Fig. 2. $\frac{3}{10}$ nat size

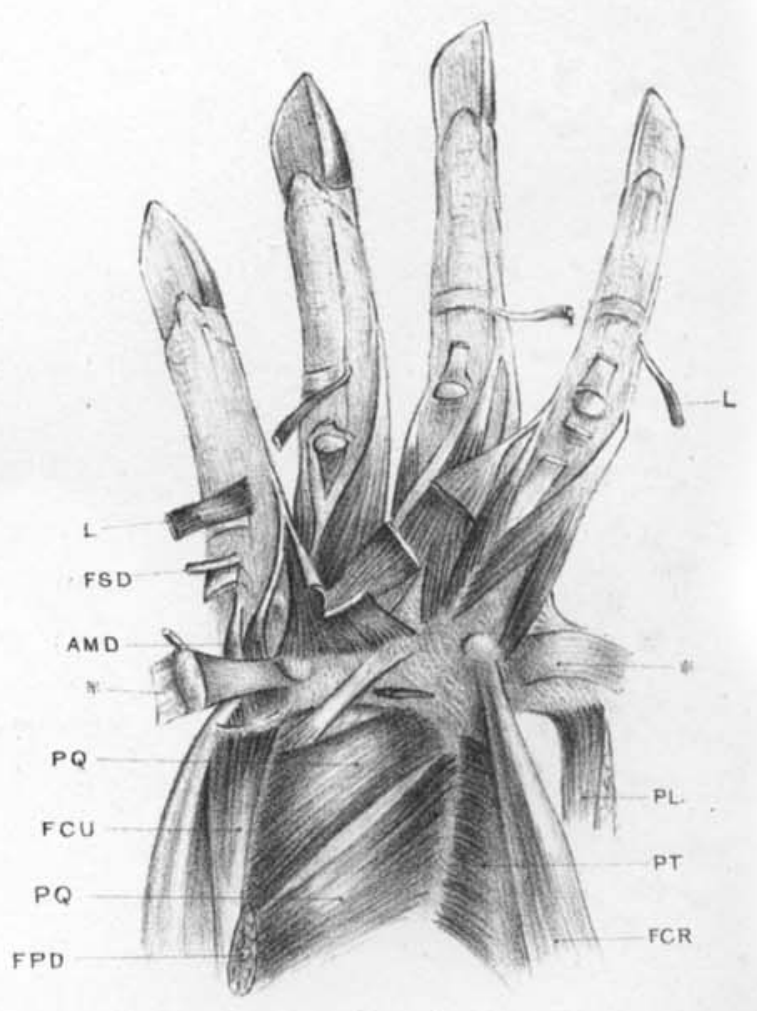

Fig. 3. as nat size 
Trans LinN Soc. Vol. XXVI.TAB. 46

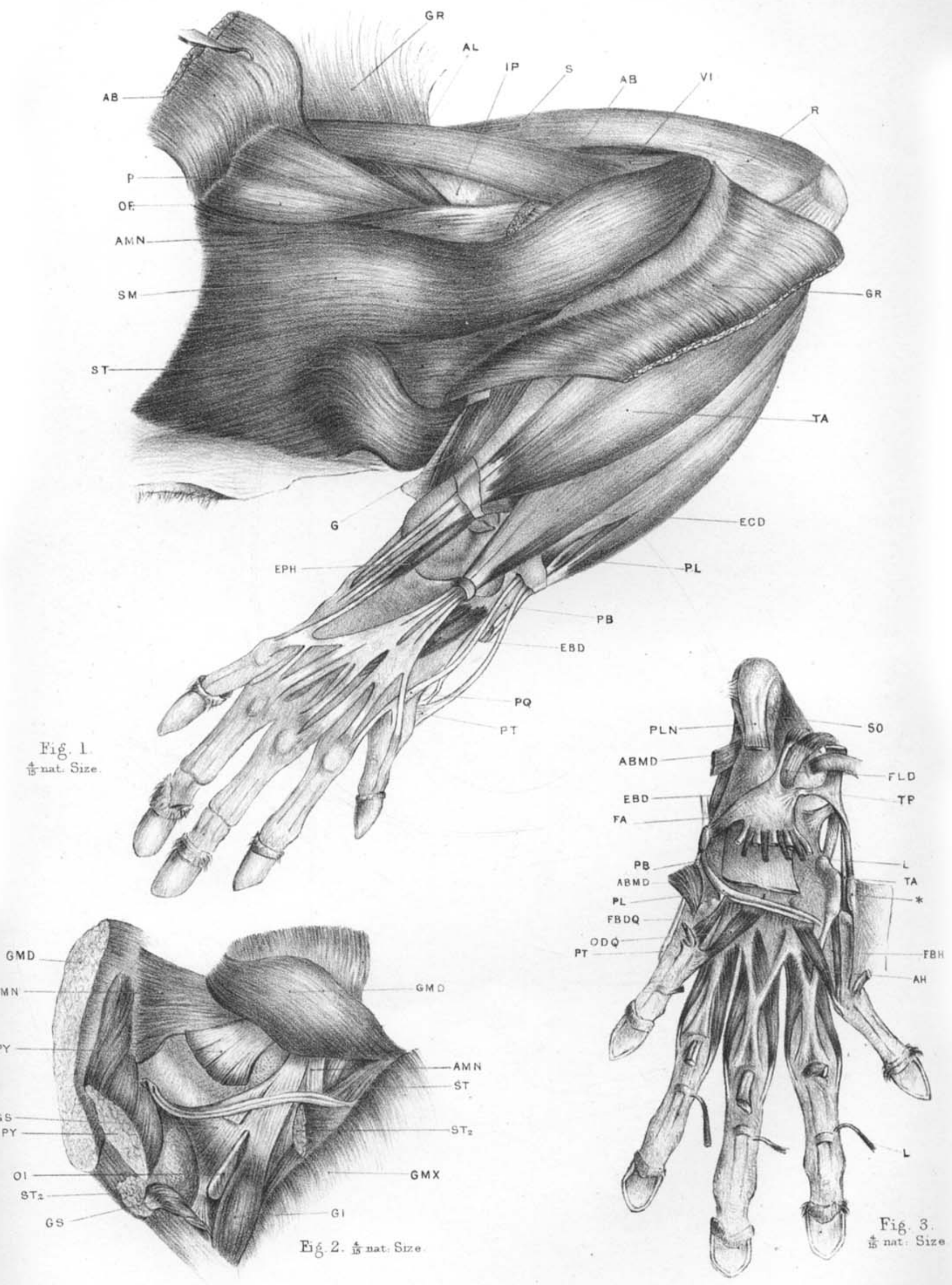

